\title{
SOME OPTICAL AND PHOTOELECTRIC PROPERTIES OF MOLYBDENITE
}

\author{
By W. W. Coblentz and H. Kahler
}

CONTENTS

I. Introductory statement ..........................................

II. Summary of previous work

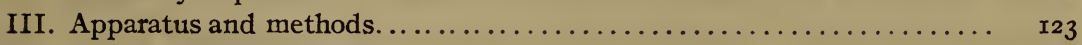

I. Diffuse-light tests. ............................. I25

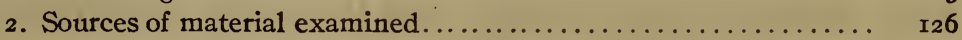

IV. Transmitting and reflecting power of molybdenite $\ldots \ldots \ldots \ldots \ldots \ldots \ldots$ r26

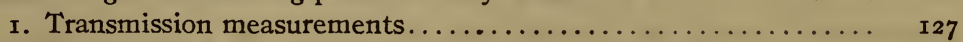

2. Reflectivity measurements. ........................ I 28

V. Variation of photoelectric current with time of exposure $\ldots \ldots \ldots \ldots \ldots \quad \mathbf{I}^{2}$

VI. Spectral range of photoelectric sensitivity ............... I34

VII. Experimental data on various samples. . . . . . . . $\ldots \ldots \ldots \ldots \ldots$

VIII. Effect of intensity of radiation upon electrical conductivity ........ I4I

IX. Effect of temperature upon photoelectric sensitivity $\ldots \ldots \ldots \ldots \ldots \ldots \ldots$

$\mathrm{X}$. Effect of humidity, vacuum, and mechanical working $\ldots \ldots \ldots \ldots \ldots \ldots$ I $\mathbf{5}^{\mathbf{I}}$

XI. Photoelectric sensitivity versus current rectification $\ldots \ldots \ldots \ldots \ldots \ldots$ I 53

I. Exudation of a dark-blue liquid $\ldots \ldots \ldots \ldots \ldots \ldots \ldots \ldots \ldots \ldots \ldots \ldots$

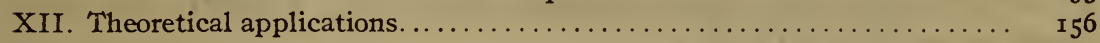

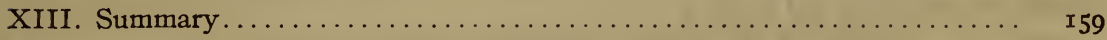

APPENDIXES:

Appendix I.--Photoelectric activity induced in unilluminated parts of a

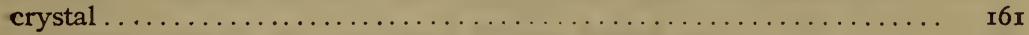

Appendix 2.-Polarization by reflection from molybdenite ......... r6r

\section{INTRODUCTORY STATEMENT}

In previous communications ${ }^{1}$ data were given on the photoelectric sensitivity of various minerals, using heterochromatic light. As it frequently happens, while this preliminary investigation was in progress, the results of a similar survey were published. ${ }^{2}$ This method of attack was therefore discontinued and the detailed investigation of the spectral photoelectric sensitivity of various substances was resumed. ${ }^{3}$

1 Proc. Phil. Soc. Wash., Feb. 3, 1917; Jour. Wash. Acad. Sci., 7, p. 525, 1917; this Bulletin, 14, p. 591, 1918.

2 Case, Phys. Rev. (2), 9, p. 305, April, 1917.

Data on selenium, potassium, etc., are given in this Bulletin, 14, p. 507, 1918. Preliminary data on molybdenite were obtained with the assistance of M. B. Long and published under joint authorship in the Phys. Rev., 11, p. 497, 1918, and 13 $_{3}$, p. 140, 1919. The latter gives data presented at the Pittsburgh meeting, Dec. 27 , I917. 
The present paper gives data on the spectral photoelectric sensitivity of molybdenite, under various conditions of operation. Molybdenite was selected for detailed examination because it is one of the few minerals available which is sufficiently homogeneous to determine various optical and electrical properties, all of which data may prove useful in arriving at an explanation of the phenomenon of change in electrical resistance of certain substances when exposed to thermal radiation.

\section{SUMMARY OF PREVIOUS WORK}

Prior to January, I9I7, but few solid substances were known which exhibited the property of changing in electrical resistance when exposed to thermal radiant energy, especially visible and ultra-violet rays. Among the substances examined were selenium, stibnite, cuprous oxide, and the halide salts of silver.

Selenium.-It is beyond the scope of this paper to attempt to summararize all the investigations made on this substance. Selenium has a very prominent maximum of photoelectric sensitivity at about $0.7 \mu(\mu=0.001 \mathrm{~mm})$ and a less intense wide band of sensitivity throughout the visible spectrum. The recent investagations of Dietrich ${ }^{4}$ show that the character of the wavelength sensitivity curve can be controlled by heat treatment. Annealing the cell at $200^{\circ} \mathrm{C}$ produces a maximum sensitivity in the extreme red, while annealing it at $150^{\circ} \mathrm{C}$ shifts the maximum sensitivity to $0.55 \mu$.

Elliot ${ }^{5}$ examined the photoelectrical sensitivity of selenium at room temperature, also at liquid-air temperature. His results show that the $0.7 \mu$ band shifts toward the short wave lengths $(0.6 \mu)$ at low temperatures. Furthermore, there is an appreciable increase in sensitivity in the infra-red producing a wide band with a maximum sensitivity at about $1.2 \mu$.

Further tests (see Fig. I) were made in the present investigation, using a Giltay selenium cell, and a fluorite prism to determine conclusively that, at room temperatures, selenium is practically insensitive throughout the infra-red spectrum to $4 \mu$.

Stibnite.-The light sensitivity of stibnite $\left(\mathrm{Sb}_{2} \mathrm{~S}_{3}\right)$ as affected by temperature has been studied by Elliot. ${ }^{\circ}$ At $20^{\circ} \mathrm{C}$ the lightsensitivity curve of stibnite is somewhat similar to the selenium curve shown in Fig. I, excepting that the maximum sensitivity occurs at about $0.75 \mu$. Lowering the temperature to $-190^{\circ} \mathrm{C}($ ?)

4 Dietrich, Phys. Rev. (2), p. 467, I9I4; 8, p. I9I, I9I6.

${ }^{6}$ Elliot, Phy. Rev. (2), 5, p. 59, I9I 5

Elliot, Phys. Rev. (2), 5, p. 53, I9I 5 . 
causes this maximum to shift to about $0.68 \mu$, and increases somewhat the sensitivity throughout the infra-red to about $2 \mu$. That stibnite is sensitive to infra-red rays even at room temperature was shown by Martin ${ }^{7}$ who observed a strong photoelectric effect produced by infra-red rays transmitted by a plate of ebonite $2 \mathrm{~mm}$ in thickness.

Cuprous Oxide.-The photoelectric sensitivity of cuprous oxide $\left(\mathrm{Cu}_{2} \mathrm{O}\right)$ was studied by Pfund. ${ }^{8}$ He found the region of greatest light sensitivity to be in the ultra-violet, near $\lambda=0.28 \mu$. A smaller maximum was observed at about $0.625 \mu$. Lowering the temperature from $19^{\circ} \mathrm{C}$ to $-127^{\circ} \mathrm{C}$ shifted this latter band toward the shorter wave lengths, $-0.6 \mu$. Using the same mate-

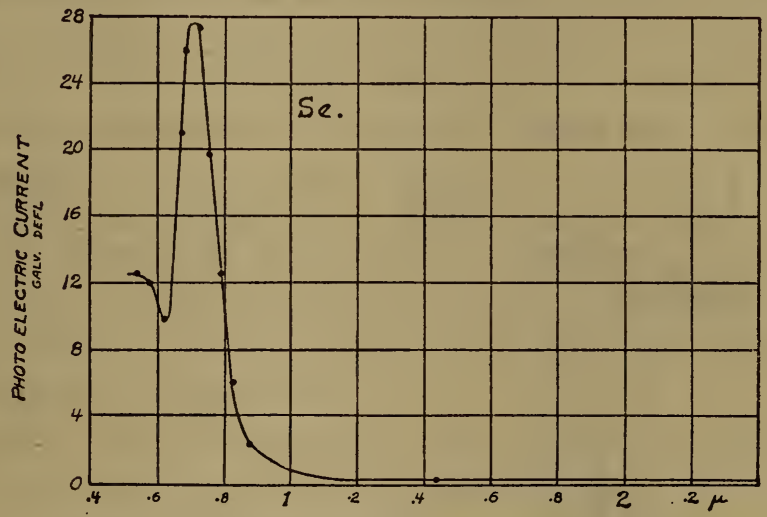

FIG. I.-Spectral photoelectric sensitivity of selenium

rial, the light-sensitivity curve depends upon the design of the cell. A further observation of importance was that the change in conductivity in cuprous oxide is limited to the portions penetrated by radiation.

\section{APPARATUS AND METHODS}

The spectroradiometric apparatus used consisted of a mirror spectrometer, a fluorite prism, and a vacuum bismuth-silver thermopile, described in previous papers. ${ }^{9}$

The source of radiation consisted of a 500-watt, gas-filled tungsten lamp securely mounted in front of the slit of the spectrometer. Using a vacuum thermopile and an accurately calibrated ammeter, the lamp was calibrated to emit equal energies throughout the spectrum. Starting in the blue-green, the lamp 
was operated at normal current (4-ampere) and the galvanometer deflection noted. This deflection was taken as a standard and for the remainder of the spectrum the current was varied so as to give the same deflection throughout the spectrum to $4 \mu$. These ammeter readings (which were as low as $\mathrm{I} .5$ amperes at about I. $6 \mu$ ) were then plotted upon coordinate paper. Several subsequent calibrations, made during the course of this investigation, showed no appreciable change in the original calibration curve.

The arrangement of the apparatus for projecting the monochromatic radiation upon the photoelectric substance is shown in Fig. 2. The radiations from the tungsten lamp, after being dispersed into a spectrum, pass through the exit slit $S$ (size 0.5 by $10 \mathrm{~mm}$ ), and, after reflection from a $50 \mathrm{~cm}$ focal length, silvered-

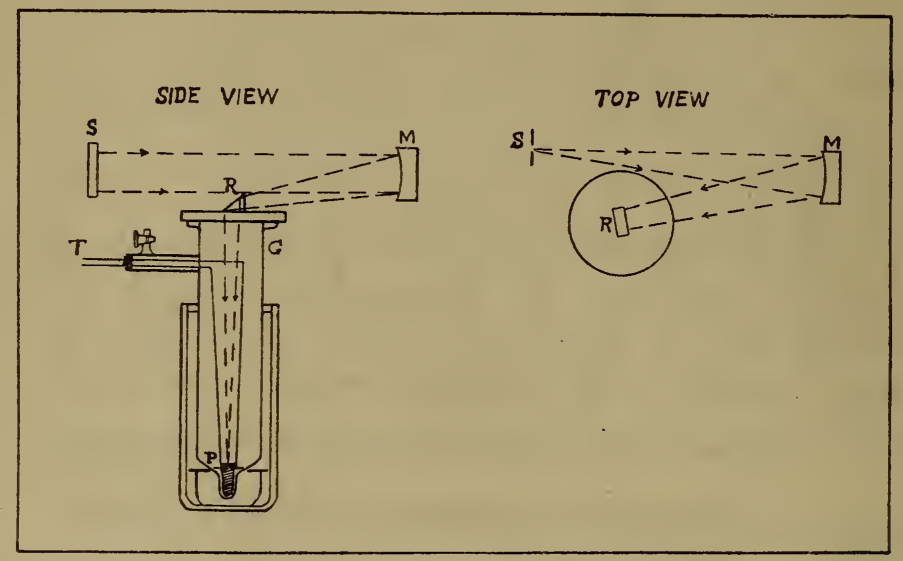

Fig. 2.-Arrangement of apparatus

glass mirror and a right-angled glass prism, are brought to focus upon the substance $P$, which is under investigation. In this manner radiations of different wave lengths, and of equal energy value ( $=$ I.I $\times$ IO- $^{6}$ watt, as determined by measurement with the thermopile placed at $P$ ) could be projected upon the molybdenite.

The crystal of molybdenite was soldered to copper electrodes (illustrated in the rectangular diagrams, in Figs. Io and II), usually mounted upon a fiber support, ${ }^{10}$ which was attached (by wire) to a heavy metal base, $P$, Fig. 2. The whole was mounted in a glass vessel $G$, about $25 \mathrm{~cm}$ in length and $5 \mathrm{~cm}$ in diameter. The copper-constantan thermocouple and the current wires leading to the molybdenite are shown diagrammatically at $T$. The 
glass container rested upon a flexible-metal support in a Dewar flask, containing liquid air, ice, or water which was heated to a definite temperature by passing an electric current through a thin strip of manganin immersed in the water.

The liquid air was replenished by means of a cardboard funnel attached to the Dewar flask, which was surrounded with cotton batting in order to maintain constant temperature conditions. After making the initial adjustments, small quantities of liquid air could be introduced into the flask without disturbing the adjustments. For most of the observations the glass vessel was evacuated. In this manner various temperatures could be obtained, which could be easily maintained constant to $0 . \mathrm{I}^{\circ} \mathrm{C}$. This is an important item in view of the fact that a change in temperature causes a change in the conductivity, and hence a change in the "dark current" through the crystal. The scale reading of the galvanometer is greatly affected by variations in the dark current.

The resistivity of molybdenite is high. The crystal was therefore operated directly in circuit with a d'Arsonval galvanometer and an electric battery of suitable voltage, which varied from 2 to 4 volts when the crystal was at room temperature to I 20 volts, at liquid-air temperature.

The sample under investigation was usually covered with a piece of thick, white cardboard, perforated by a slit (0.5 by ro $\mathrm{mm}$.) which enabled the observer to expose a definite part of the crystal to radiation.

The method of observation consisted in setting the spectrometer circle so as to permit radiation of a given wave length to pass out through the slit $S$, and from thence to the crystal $P$. The ammeter was set to the proper value as determined by the calibration curve. The shutter was then raised and the crystal exposed to the radiation stimulus for an unlimited time, which varied from 5 seconds for visible radiations to 6 to 12 minutes for infra-red rays.

\section{DIFFUSE-LIGHT TESTS}

The novelty of finding bands of photoelectric sensitivity far beyond the range heretofore observed in the infra-red raised the question whether this might be owing to scattered radiations. Tests were therefore made using glass screens ${ }^{11}$ (e. g., Corning $\mathrm{G}_{585}$ ), which absorbed all radiations except those at I $\mu$. By 
means of the thermopile the lamp was calibrated to emit the same energy with and without the glass screen in place before the spectrometer slit. Repeated tests showed that within less than I per cent the scattered light had no effect on the shape and position of the bands of photoelectric sensitivity observed at I to $1.2 \mu$. The observations were therefore made without employing additional screens for absorbing scattered light.

\section{SOURCES OF MATERIAL EXAMINED}

The majority of the samples examined, 18 in all, were obtained from the United States National Museum. Some were obtained from mineral dealers. The localities from which they had been obtained were Alaska, Australia, Canada, Japan; and in the United States, California, Colorado, Maine, Montana, Vermont, and Washington. From preliminary sensitivity tests, made with a photophone consisting of a rotating sector, telephone, and an audion amplifier, using high intensities, it was found that all the material was of low resistance and low or uncertain photoelectric sensitivity, except certain samples obtained from Yorkes Peninsula, South Australia. Projecting an image of a point source of light upon the samples showed that the photoelectric sensitivity was usually localized in spots as shown in Figs. ro and I , and as previously found in bismuthinite. ${ }^{12}$.

\section{TRANSMITTING AND REFLECTING POWER OF MOLYBDENITE}

As already mentioned, molybdenite is unusually well adapted for investigating the bearing of various physical properties upon photoelectrical sensitivity. It was therefore of interest to determine whether there is any close relation between the optical and photoelectrical properties of this substance. For this purpose the spectral transmission and reflection of several samples were determined by means of the spectroradiometric apparatus used in the photoelectric work.

On the supposition that photoelectric activity is a resonance phenomenon, Pfund ${ }^{13}$ sought a relation between thermal radiant energy absorbed and change in electrical conductivity. On this basis he should have found the greatest photoelectrical activity of selenium in the blue, where the absorption was the greatest. This deduction was not verified by experiment, which showed 
that the maximum photoelectric sensitivity of selenium is in the red.

Previous investigations ${ }^{14}$ show that molybdenite has a low transmission in the visible spectrum, followed by great transparency and high reflectivity in the infra-red. A decrease in temperature to boiling liquid air greatly increases the transparency of molybdenite. Crandall quotes observations, made by Trowbridge, showing that a sample of molybdenite which was transparent down to $0.702 \mu$, at room temperature, became transparent down to $0.666 \mu$, at $-190^{\circ} \mathrm{C}$. This is of interest in connection with the observations of a shift of the position of maximum

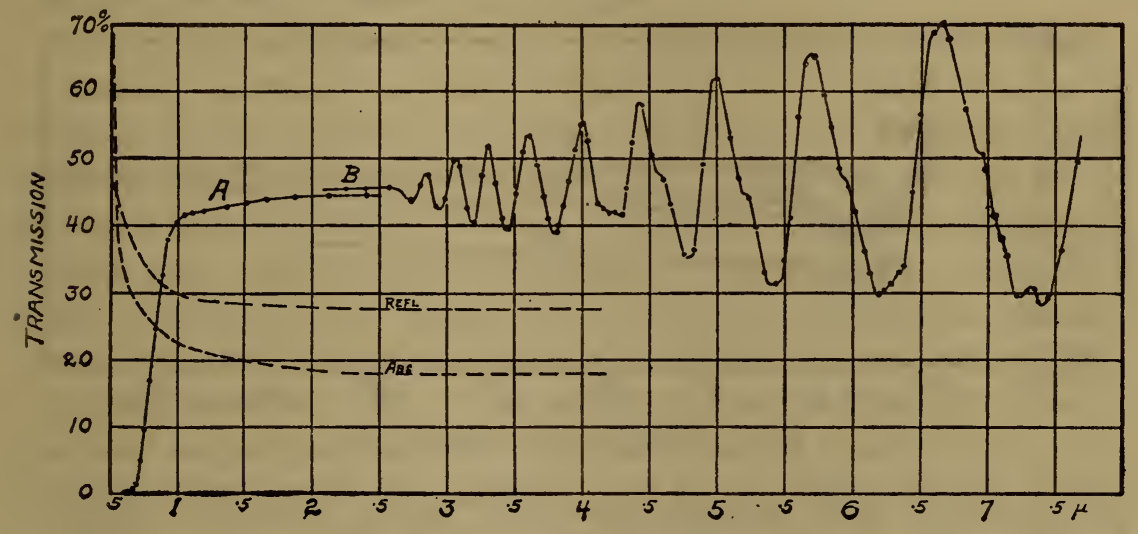

Fig. 3.-Transmission of molybdenite

photoelectric activity toward the short wave lengths with decrease in temperature.

\section{TRANSMISSION MEASUREMENTS}

The transmission of a sample of molybdenite $(0.007 \mathrm{~mm}$ in thickness ${ }^{15}$ ) is given in Fig. 3. This sample transmitted only the red end of the visible spectrum. Beyond $\mathrm{r} \mu$ the transmission is uniform, as previously observed. The data published by Crandall, ${ }^{16}$ who eliminated the losses by reflection by making measurements on two samples of different thickness, show that beyond I $\mu$ the absorption decreases abruptly to a low, uniform value. (See Fig. 3.) As will be noticed presently, the greatest photo-

\footnotetext{
14 Coblentz, Publication No. 97, Carnegie Institute, Washington, pp. ${ }_{3}$ and 4r, 1908; Crandall, Phys. Rev. (2), 2, p. 343, 1913.

15 The transmissivity observations were obtained with the assistance of $\mathrm{M}$. B. Long, and published in this Bulletin, 14, p. 653; 19r8. The thickness was determined by L. V. Judson of the weights and measures division, using an end comparator. The specimen was pressed on a Johannson block by means of a plunger having an optically flat contact surface $2 \mathrm{~mm}$ in diameter, the pressure being $200 \mathrm{~g}$.

${ }^{16}$ Crandall, Phys. Rev. (2), 2, p. 343; 1913.
} 
electric activity of molybdenite occurs in the region of the spectrum where the absorption is changing rapidly, from which it would appear that, as previously had been observed to a more limited extent, the connection between optical absorption and photoelectrical activity is rather intricate.

The wavy character of the transmission curve beyond $2.5 \mu$ is the result of interference bands. It is of interest in showing the resolving power of the apparatus. Curves of this type are of interest to students in physical optics in connection with the question of interference and the conservation of energy. The reflectivity curve of a somewhat thinner sample was published

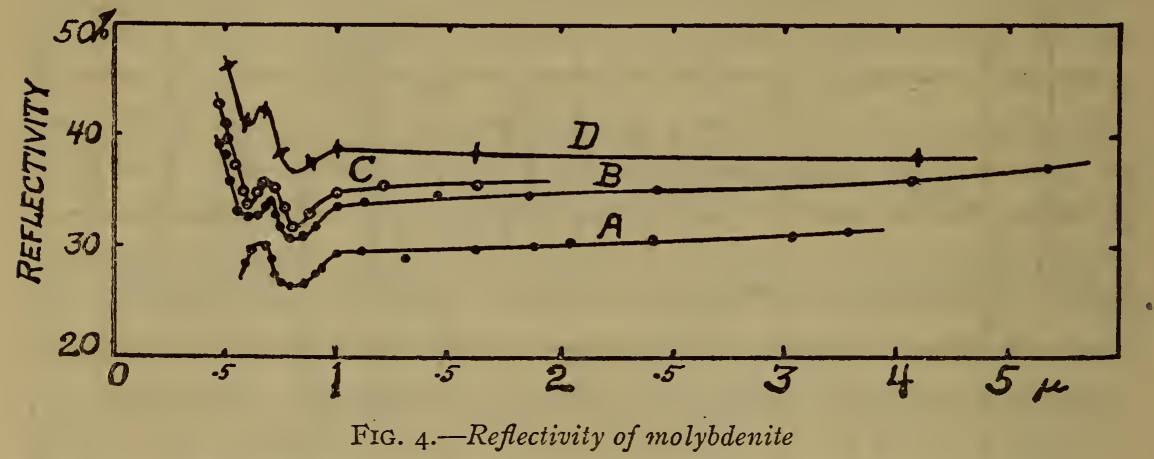

by Crandall ${ }^{17}$ who has calculated the optical constants of this mineral.

\section{REFLECTIVITY MEASUREMENTS}

In the present experiments the reflecting power of molybdenite was determined by comparison with a silver-on-glass mirror, correction being applied for absorption in the silver. The material examined was National Museum sample No. 53046, from Wakefield, Canada. The mirrors were made by pressing thin laminæ of molybdenite upon plate glass. This produced smooth surfaces quite free from identations.

In Fig. 4, curve $A$ gives the reflecting power of a sample $0.1 \mathrm{~mm}$ in thickness. Curve $B$ gives the reflectivity of a sample $0.3 \mathrm{~mm}$ in thickness, having a higher polish. In order to establish more thoroughly the indentations in the reflectivity curve at $\lambda=0.54 \mu$ and $\lambda=0.63 \mu$, as well as the higher reflecting power in the violet, the silver mirror was replaced by a right-angled glass prism ${ }^{18}$ which is nonselective in its reflection. The data obtained on this same sample, using the glass-prism reflector, are illustrated in curve $C$. 
On removing this sample from its mounting a thin, flat lamina adhered to the glass. The polish of this cleavage surface was higher than one could obtain by rubbing the surface, and the reflecting power is probably as near to the true value as can be attained.

These observations show that the reflecting power of molybdenite is highly selective in the visible spectrum, decreasing from 46 per cent at $0.5 \mu$ to a much lower value at $\mathrm{I} \mu$, beyond which point the reflectivity is fairly uniform, as previously observed. This selective reflection is easily demonstrated by pressing a thin plate of molybdenite into a $V$-shaped cavity, which appears a brilliant indigo-blue when viewed in daylight.

The previous measurements ${ }^{19}$ of reflecting power were made on a massive sample 2 to $3 \mathrm{~cm}$ in thickness. The polish was not as high as in the present work. For long waves, however, the question of polish is not a serious matter. The data then obtained indicate a reflectivity of 20 to 22 per cent, which is considerably lower than observed in the present measurements. The observations at long wave lengths where scattering is low indicate that the true reflectivity of this sample could not be very much higher than the observed value. The sample was of sufficient thickness to prevent augmentation of the reflected light by internal reflection. On the other hand, the samples used by Crandall, as well as the samples used in the present investigation, are so thin and the absorption is so low that radiations which enter the sample are reflected at the second surface, and returning (without great diminution in intensity) emerge and cause the observed reflectivity value to be higher than the true value. That this really occurs is shown in Table I and in the dotted curves Refl and $A b s$, in Fig. 3; also curve $D$, Fig. 4. These two samples had their natural cleavage surfaces untouched; hence their reflection is closely the same. Assuming five internal reflections for computing the reflectivity and four internal reflections for computing the transmitted radiations, and using the values given in Table I (where $A=$ the per cent absorption in traversing once through the layer; say $A=20.5$ per cent and $r=28.8$ per cent at $\lambda=1.3 \mu$ ) it is found that the observed transmission and reflection data are accurately reproduced. At $0.5 \mu$ there is complete opacity and the observed reflecting power ( $R=46$ per cent) is the true value. On the basis of this computation the true reflecting power, $r$ (Table $\mathrm{I}$ ),

19 Publication No. 97, Carnegie Institution of Washington; I908. 
of molybdenite is illustrated by the dotted curve Refl in Fig. 3 . which is more nearly in agreement with the previous observations, The absorption produced in traversing once through the layer is illustrated in the curve marked $A b s$ in Fig. 3 ; complete absorption occurred at wave lengths less than $0.5 \mu$. These calculations indicate that the true reflecting power is of the order of 28 to 30 per cent instead of 38 to 40 per cent, as observed.

TABLE 1.-Transmission, Reflection, and Refractive Index of Molybdenite

[Key to symbols: $A=$ the assumed per cent of entering light absorbed in traversing the thickness of the layer; $r=$ the assumed per cent of incidentlight reflected at the first surface; $R=$ summation of returning light; $T=$ summation of transmitted light; $n=\frac{1}{!-r}(1+r \pm \sqrt{4 r})$.

\begin{tabular}{|c|c|c|c|c|}
\hline & $\lambda=1 \mu$ & $1.3 \mu$ & $2.2 \mu$ & $4 \mu$ \\
\hline A.. & 22.3 & 20.5 & 18.1 & 18.1 \\
\hline$r \ldots$ & 29.8 & 28.8 & 27.8 & 27.8 \\
\hline$R$ (observed) $\ldots \ldots \ldots \ldots \ldots \ldots \ldots \ldots \ldots \ldots \ldots \ldots$ & 39.0 & 38.5 & 38.1 & 38.0 \\
\hline$R$ (computed) $\ldots \ldots \ldots \ldots \ldots \ldots \ldots \ldots \ldots \ldots$ & 39.1 & 38.5 & 38.0 & 38.0 \\
\hline 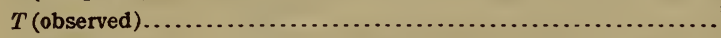 & 40.5 & 42.5 & 45.0 & 45.0 \\
\hline 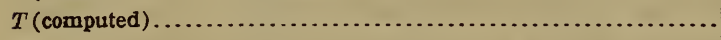 & 40.5 & 42.5 & 45.0 & 45.0 . \\
\hline 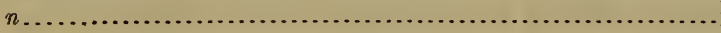 & 3.40 & 3.30 & 3.23 & 3.23 \\
\hline
\end{tabular}

Using the values of $r$ illustrated in Fig. 3, and neglecting the extinction coefficient, the refractive index $n$ is computed on the basis of $r=\left(\frac{n-I}{n+I}\right)^{2}$. These values of $n$ are given in Table $\mathrm{I}$. They are somewhat larger than similar data computed from the interference bands shown in Fig. 3, employing the formula

$$
n=\frac{N \lambda_{1} \lambda_{2}}{2 t\left(\lambda_{2}-\lambda_{1}\right)}
$$

in which $N$ is the number of bands between $\lambda_{1}$ and $\lambda_{2}$ (see column 3 , Table 2), and using the observed thickness of $t=0.007 \mathrm{~mm}$. Using $t=0.006 \mathrm{~mm}$ gives values of $n$ which are $\mathrm{I} 2$ per cent larger, corresponding more nearly with the values given in Table $\mathbf{I}$.

Computations of $n$ are given also, utilizing single maxima or minima, and remembering that the difference in optical length of path for interference in transmission is $2 n t$ or about $42 \mu$. Following the method of computation given by Crandall, using the formula $2 n_{1} t=N_{1} \lambda_{1}$, and taking the values of $N_{1}$ given in Table 2 , the corresponding values of $n_{1}$ were obtained. (See columns 5 and 9 of Table 2.) 
In making these computations it is assumed that the small indentations (e. g., $4.6 \mu, 5.2 \mu$ ) are a second series of interference bands, the origin of which is undetermined. Only the bands given in columns 2 and 6 of Table 2 were used.

TABLE 2.-Refractive Indices of Molybdenite Computed by Formulas Given in Text, Using Transmission Minima or Maxima

\begin{tabular}{|c|c|c|c|c|c|c|c|c|}
\hline \multicolumn{5}{|c|}{ Minima } & \multicolumn{4}{|c|}{ Maxima } \\
\hline$\lambda$ & $\lambda_{1}$ & $n$ & $N_{1}$ & $n_{1}$ & $\lambda_{1}$ & $n$ & $N_{1}$ & $n_{1}$ \\
\hline 2.72 & 2.72 & ......... & 14.5 & 2.82 & 2.85 & ...... & 14 & 2.85 \\
\hline 2.94 & 2.94 & 2.64 & 13.5 & 2.83 & 3.07 & 2.98 & 13 & 2.83 \\
\hline 3.19 & 3.19 & 2.89 & 12.5 & 2.85 & 3. 30 & 2.98 & 12 & 2.83 \\
\hline 3.44 & 3.44 & 2.88 & 11.5 & 2.83 & . & .. & .... & $\cdots$ \\
\hline $3.66 a$ & ........ & ;.... & ...... & ....... & 3.60 & 2.70 & 11 & 2.83 \\
\hline 3.80 & 3.80 & 2.66 & 10.5 & 2.85 & ..... & ${ }^{\prime \ldots .}$ & $2 \ldots$ & .... \\
\hline 4.07 & $\cdots$ & ...... & ;..... & ........ & 4.00 & 2.77 & 10 & 2.85 \\
\hline 4.30 & 4.22 & 2.59 & 9.5 & 2.86 & 4.42 & 2.88 & 9 & 2.84 \\
\hline 4.53 & & & $\cdots$ & $\cdots$ & & & & \\
\hline 4.77 & 4.79 & 2.74 & 8.5 & 2.91 & $\cdots \cdots$ & ...... & $\cdots$ & $\cdots$ \\
\hline $4.96 a$ & $\cdots$ & & .... & ........ & 4.99 & 2.81 & 8 & 2.85 \\
\hline 5.20 & & $\cdots$ & $\cdot$ & ... & $\ldots$ & & & \\
\hline 5.44 & 5.41 & 2.85 & 7.5 & 2.90 & ... & & ... & $\cdots$ \\
\hline $5.68 a$ & & & & & 5.70 & 2.88 & 7 & 2.85 \\
\hline 5.94 & & & & & ..... & & .. & \\
\hline 6.18 & .... & $\ldots$. & $\ldots$ & ....... & & & & \\
\hline 6.40 & 6.30 & 2.93 & 6.5 & 2.92 & & & •. & \\
\hline 6.65 & $\ldots$ & $\cdots$ & $\cdots$. & & 6.65 & & 6 & 2.85 \\
\hline 6.93 & & & & & & & & \\
\hline 7.20 & ..... & & ... & .... & & & & \\
\hline 7.45 & 7.35 & & 5.5 & 2.89 & & & & \\
\hline
\end{tabular}

$a=$ Missing.

Using consecutive bands gives values of $n$ which increase in value to $n=\mathrm{I} 4$ at $\lambda=7 \mu$. This is inconsistent in view of the constancy of the absorption and reflection data. The region of anomalous dispersion is at $0.5 \mu$, beyond which point the refractive index should decrease.

These data are somewhat different from those published by Crandall. ${ }^{20}$ It is to be noticed that, comparing data obtained on samples having practically the same thickness, twice as many interference bands were observed in the present examination. The common difference between these bands is about $0.23 \mu$, whereas Crandall's curves show bands separated by about $0.45 \mu$ to $0.5 \mu$ or multiples of this number. 


\section{VARIATION OF PHOTOELECTRIC CURRENT WITH TIME OF EXPOSURE}

It is well known that the photoelectric response of selenium lags considerably more for infra-red rays than for visual rays. Molybdenite is much quicker than selenium in its photoelectric response (change in electrical conductivity) when exposed to radiation, irrespective of wave length.

In view of the far greater range of sensitivity in the infra-red than heretofore observed, it is of interest to give the responsetime curves of molybdenite for various wave lengths.

Fig. 14, curve $A$, gives the spectral photoelectric sensitivity of molybdenite when exposed for ro seconds, while curve $B$ gives

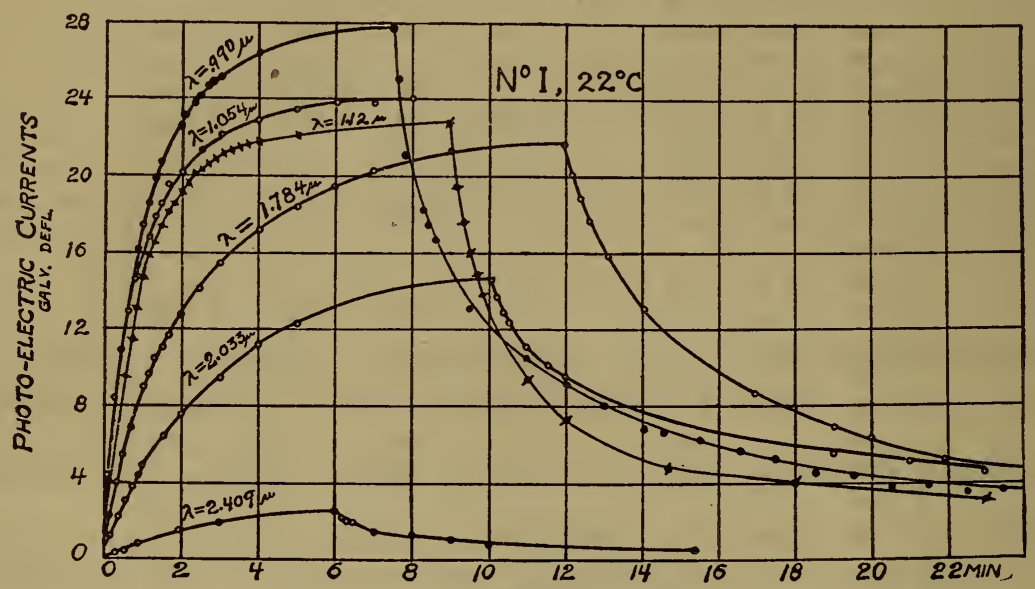

FIG. 5.-Variation of photoelectric current with time of exposure to radiation

the corresponding curve for unlimited exposure; that is, exposure until there is no further increase in the galvanometer deflection.

At $\lambda=0.76 \mu$ the difference in photoelectric current (galvanometer deflection) for limited exposure and for unlimited exposure (which at this point was about 30 seconds) was very small. On the other hand, beyond $\lambda=\mathrm{I} .4 \mu$ the response is so slow that, on a Io-second exposure, the photoelectric sensitivity appears to be inappreciable.

In Fig. 5 a series of response-time curves are given, showing the variation in conductivity (photoelectric current) with time of exposure to the radiation stimulus and the rate of recovery of the sample to its original resistance. The data show that in the yellow part of the spectrum equilibrium in electrical conductivity is attained after 5 to ro seconds exposure. This exposure 
time increases very rapidly after passing beyond $\lambda=0.75 \mu$ where an exposure of about 30 seconds is required. The time for recovery is prolonged to about two times the exposure time for equilibrium. In making the observations, twice the exposure time was therefore allowed for recovery of the original conductivity.

Experiments ${ }^{21}$ show that at low temperatures the increase in conductivity of selenium when exposed to light, and the recovery after exposure, is markedly slower than at ordinary temperatures. It is of interest, therefore, to notice the behavior of molybdenite at low temperatures. As shown in Fig. 6, lowering the temperature has no marked influence upon the rate of response (conductivity) of molybdenite when exposed to radiation; nor is the time of recovery markedly different from that observed at room temperature. By a marked difference in response and recovery is meant a factor of two or three times the time ( 8 to 12 minutes) indicated in Fig. 5. A delay of one to three minutes for recovery at liquid-air temperatures, as compared with room temperatures, is not to be considered in view of the very rapid change in dark current (zero shift of scale reading) owing to a slight change in temperature, which could not be maintained constant closer than about $0.03^{\circ} \mathrm{C}$.

From a casual inspection of Fig. 5 it might be inferred that it required a longer time of exposure to radiations of wave length $\lambda=1.784 \mu$ than for $\lambda=2.033 \mu$ in order to obtain conductivity equilibrium. In reality the upward trend of the curve for $\lambda=2.033 \mu$ shows that equilibrium had not yet been attained after ro minutes exposure, and that a longer exposure should have been made. However, for practical purposes it was better to terminate the exposure at this point in view of the possibility of losing by zero shift (temperature change) what might have been gained in conductivity change by further exposure of the sample to radiation.

In Fig. 6 the scale of galvanometer deflections for $\lambda=1.357 \mu$ is magnified four times.

In practice it was the custom to allow twice the exposure time for recovery. The fact that in making a series of observations there was no continuous zero shift in one direction would indicate that allowing twice the exposure time for recombination was sufficient for complete recovery to the original dark resistance.

${ }^{21}$ McDowell, Phys. Rev., 23, p. 524, rgro.

$111676^{\circ}-19-3$ 


\section{SPECTRAL RANGE OF PHOTOELECTRIC SENSITIVITY}

The first tests of photoelectric sensitivity of molybdenite were made by using wide bands of spectra! energy obtained by using glass screens, ${ }^{22}$ residual rays, etc. By this means it was possible to obtain radiant energy stimuli of wave lengths ranging from $\lambda=0.365 \mu$ in the ultra-violet to $\lambda=9 \mu$ in the remote infra-red.

When using the transmission glasses the source of light was either a Nernst glower or a quartz mercury vapor lamp. The energy was measured by means of a thermopile.

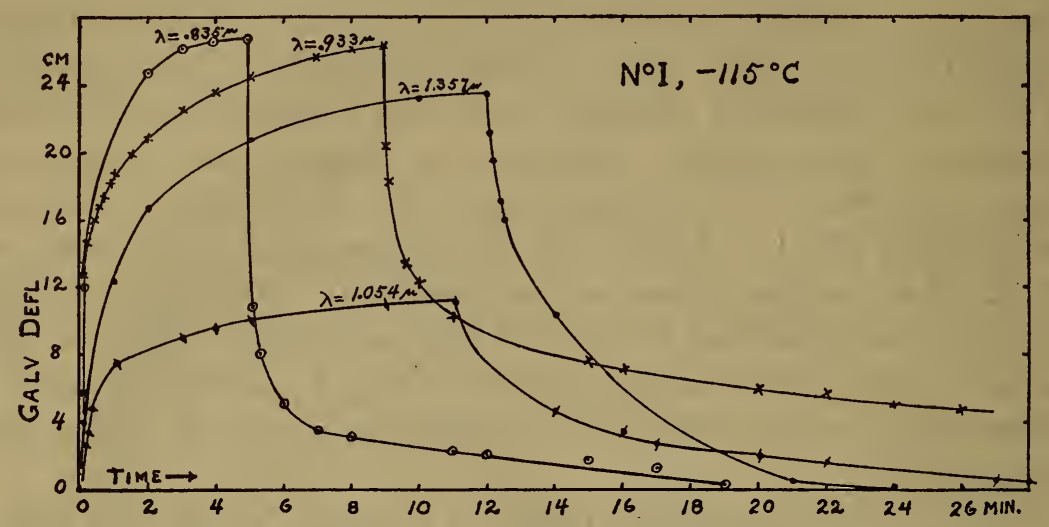

FIG. 6.-Variation of photoelectric current with time of exposure to radiation

For making this examination the following regions of the spectrum were utilized:

I. That part of the spectrum transmitted through a 5 per cent solution ${ }^{23}$ of cupric chloride in a cell $2 \mathrm{~cm}$ in thickness and a plate of Corning glass, $\mathrm{G}_{55}, \mathrm{~A}_{62}$ (new number $\mathrm{G}_{586}$ ). The maximum of the transmitted energy lies in the ultra-violet at about $\lambda=0.36 \mu$. Insertion of a piece of red glass showed that all of the observed photoelectrical activity was caused by the ultraviolet rays from the mercury vapor lamp. A subsequent test showed conclusively that molybdenite at room temperature, at least, is less sensitive in the ultra-violet $(\lambda=0.36 \mu)$ than in the visible spectrum, as shown in Fig. I4.

2. By using a $2 \mathrm{~cm}$ cell of water and Crookes's sage-green (ferrous No. 30) glass, a fairly monochromatic band is obtained, having its maximum intensity at $\lambda=0.53 \mu$.

22 This Bulletin, 14, p. 653, I918. Some of the photoelectric data obtained by this method were given at the Pittsburgh meeting, Amer. Assn. Adv. Sci., Dec., I9I7 (see Phys. Rev., I3, p. I40, I9I9).

${ }^{23}$ Bulletin, 7, p. 6rg, Igri; 9, p. Iro, I9I2. 
3. Using a Corning Noviweld glass "shade 30 per cent," a 2 $\mathrm{cm}$ water cell, and a Nernst glower, regulated to give equal energies throughout the spectrum, the maximum intensity of the light stimulus was at about $\lambda=0.56 \mu$.

4. Using Corning purple glass, $\mathrm{G}_{55}, \mathrm{~A} 62$, Schott's red glass, 2745 , and a $2 \mathrm{~cm}$ cell of water, gave a transmission band having its maximum intensity at $\lambda=0.77 \mu$.

5. Using Corning blue-purple glass $\mathrm{G}_{5} 85$, Schott's red glass, 2745 , and a $2 \mathrm{~cm}$ cell of water (when using the Nernst glower below normal operation) gave a band of maximum transmission at about $\lambda=0.85 \mu$.

6. Using three sheets of electric-smoke glass gave a wide band of spectral energy with a maximum at about $2.2 \mu$.

7. The radiation from a Bunsen flame gave an emission band with maximum at $4.4 \mu$.

8. The residual rays obtained by reflection from two surfaces of quartz, using a Nernst glower as a source, gave two intense bands of selective reflection, $8.5 \mu$ and $9.05 \mu$, respectively, the mean value being about $\lambda=8.8 \mu$.

Using equal energies, the data obtained by this method showed that molybdenite is somewhat photoelectrically sensitive in the violet, and has a maximum of sensitivity at about $\mathrm{I} \mu$ in the infrared. An indentation in the curve indicated a possible maximum (No. I was used, see Fig. 7) at $\lambda=0.75 \mu$, as was demonstrated conclusively in a later examination. A fairly high sensitivity was indicated at $2.2 \mu$. The Bunsen flame caused a small change in electrical conductivity. This was probably produced by radiations of wave length $1.8 \mu$ and $2.7 \mu$. A subsequent examination using the spectrometer showed no sensitivity at 3 to $4 \mu$.

As indicated elsewhere, ${ }^{24}$ the most important contribution to be made by this test was to establish to what extent this decrease in electrical resistance is caused by rise in temperature when exposed to radiation. The measurements, using radiations dominating at $\lambda=8$ to $9 \mu$ are useful in settling this question. Since the reflection and absorption of molybdenite is uniform throughout the spectrum the application of equal energies of different wave lengths should produce approximately the same thermal change, irrespective of the wave length.

Using radiations of wave length $\lambda=8$ to $9 \mu$, the photoelectric effect produced a galvanometer deflection of 15.5 to $16 \mathrm{~mm}$. On 
inserting a plate of clear glass, which is opaque to radiations of wave length greater than $4 \mu$, the deflection was $14.5 \mathrm{~mm}$, indicating that the photoelectric effect is produced by scattered radiations of wave length less than $4 \mu$. Moreover, it is caused entirely by the energy of wave lengths less than $4 \mu$. For, correcting for losses by reflection and absorption which amount to 8 to 9 per cent in the glass plate, the deflection is increased from I 4.5 to $15.8 \mathrm{~mm}$, which is in agreement with the observations made without the glass.

The conclusions to be drawn from these experiments are that molybdenite is not photoelectrically sensitive to infra-red rays of wave lengths $\lambda=8$ to $9 \mu$, and that the observations at the shorter

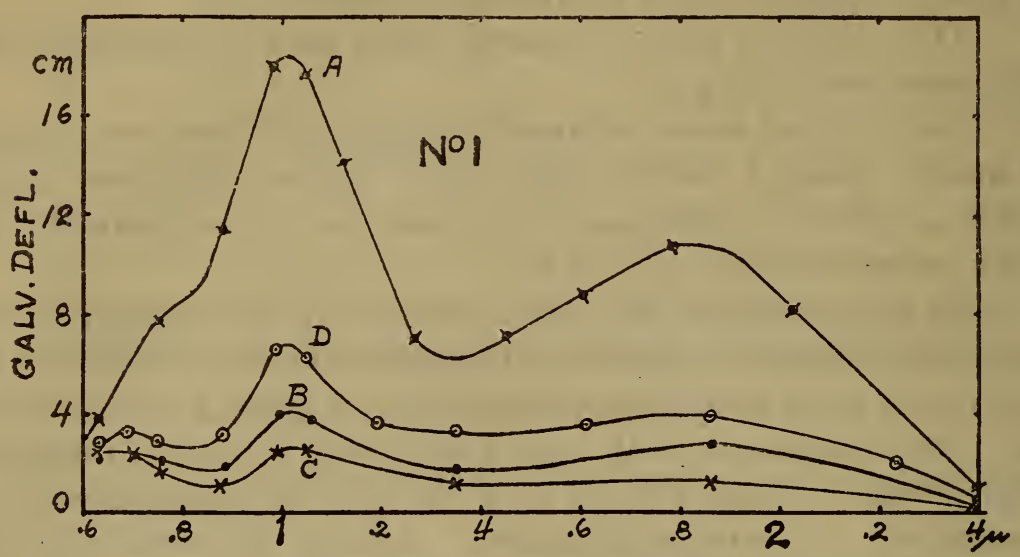

FIG. 7.-Spectral photoelectric sensitivity of different parts of a crystal of molybdenite

wave lengths were not affected by the purely thermal changes produced on exposure to radiation.

\section{EXPERIMENTAL DATA ON VARIOUS SAMPLES}

Unless otherwise stated, the samples examined were selected from material obtained from Yorkes Peninsula, South Australia. They were numbered consecutively as investigated. Their dimensions and resistances are given in Table 3 . Under the present caption are given additional particulars and comments relative to the behavior of these samples.

In all these illustrations, unless otherwise stated, the samples were exposed in the glass container $P$, shown in Fig. 2.

In these illustrations the ordinates represent the observed galvanometer deflections, which are proportional to the change in electrical conductivity caused by the energy stimulus. 
TABLE 3.-Dark Resistance of Molybdenite Samples Against Direction of Current

[Key to symbols: $L=$ Length; $W=$ width; $T=$ thickness in centimeters; $S P . R=\frac{\text { Resistance }}{C^{3}} ; R$ and $R^{1=}$ ohmic resistance in opposite directions. Source. $-A=A$ ustralia; $A l=A l a s k a ; C=C a n a d a ; J=J a p a n$; Col= Colorado. $]$

\begin{tabular}{|c|c|c|c|c|c|c|c|c|c|c|}
\hline No. & Source. & $R$ & $R^{1}$ & $R-R^{\prime}$ & $\frac{R-R^{1}}{R}$ & $L$ & $W$ & $T$ & $S P . R$ & $S P \cdot R^{1}$ \\
\hline & & 640000 & 625000 & 15000 & 2.3 & 0.6 & 0.4 & & & \\
\hline $2 .$. & A. & 1340000 & 1135000 & 205000 & 15.3 & .8 & .4 & 0.004 & 2680 & 2270 \\
\hline $4 .$. & A. & 457000 & 443000 & 14000 & 3.1 & .8 & .2 & .011 & 1255 & 1215 \\
\hline 5. & A. & 600000 & 590000 & 10000 & 1.7 & ...... & ...... & ...... & ...... & ..... \\
\hline 6.. & A. & 590000 & 515000 & 75000 & 12.7 & .7 & .4 & .008 & 2690 & 2350 \\
\hline 7. & A. & 1670000 & 1640000 & 30000 & 1.8 & $\ldots$ & ...... & ...... & $\cdots$ & $\cdots$ \\
\hline 8. & A. & 100000 & 92000 & 8000 & 8 & .6 & .5 & .006 & 500 & 460 \\
\hline $9 .$. & A. & 448000 & 440000 & 8000 & 1.8 & .7 & .4 & .003 & 758 & 751 \\
\hline $10 .$. & A. & 4000000 & 3900000 & 100000 & 2.5 & .6 & .35 & .006 & 14000 & 13700 \\
\hline $11 .$. & A. & 3300000 & 2100000 & 1200000 & 36.4 & .8 & .5 & .008 & 16500 & 10500 \\
\hline $12 .$. & A. & 540000 & 463000 & 77000 & 14.3 & .6 & .5 & 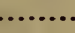 & $\cdots$ & $\cdots$ \\
\hline 13. & A. & 334000 & 329000 & 5000 & 1.5 & .7 & .3 & & & \\
\hline $14 .$. & A. & 675000 & 570000 & 105000 & 15.6 & .8 & .3 & & *... & ....... \\
\hline $15 .$. & A.. & 1050000 & 1000000 & 50000 & 4.8 & .8 & .35 & .007 & 3220 & 3060 \\
\hline 16. & A. & 9900000 & 5000000 & 4900000 & 49.5 & .5 & .3 & & & \\
\hline $17 .$. & A. & 820000 & 790000 & 30000 & 3.7 & .8 & .4 & .... & $\cdot \cdot \cdot$ & $\cdots$ \\
\hline 18. & Al. . & 54000 & 16400 & 37600 & 69.6 & .8 & .3 & .005 & 101 & 30.7 \\
\hline 19. & Al. . & 8500 & 4300 & 4200 & 49.4 & 1.1 & .3 & .005 & 11.6 & 5.86 \\
\hline $20 a$. & C.. & 1760 & 1760 & 0 & 0 & 1.2 & .3 & .006 & 2.6 & 2.6 \\
\hline $21 a$ & C... & 9470 & 9470 & 0 & 0 & 1.5 & .5 & .005 & 15.8 & 15.8 \\
\hline $22 a$ & J.. & 2875 & 2875 & 0 & 0 & .68 & .35 & .006 & 8.9 & 8.9 \\
\hline $23 a$ & C. . & 69800 & 69800 & 0 & 0 & .9 & .12 & .001 & 10 & 10 \\
\hline $24 a$ & C.. & 20900 & 20900 & 300 & 1.4 & .85 & .17 & .002 & 8.5 & 8.5 \\
\hline $25 a$ & Col. & 17210 & 16980 & 230 & 1.3 & .87 & .12 & .004 & 9.5 & 9.4 \\
\hline
\end{tabular}

$a=$ nonsensitive.

Sample No. I.-In Fig. 7 curve $A$ gives the spectral photoelectric sensitivity when this sample was mounted directly in front of the spectrometer slit $S$, Fig. 2, and hence observed at a somewhat higher intensity than curve $D$, which was observed when the sample was in the glass container.

The mounting of this specimen happened to be perforated, permitting irradiation of the rear surface of the molybdenite. Curves $B$ and $C$ show the change in electrical conductivity when an edge and central portion of the rear side were exposed to radiation.

As will be noticed in subsequent tests of other samples, the position of the maxima and their relative intensities as well as their absolute intensities depend upon the part of the crystal exposed. This sample has maxima at wave lengths $\lambda=0.72 \mu$, I. $02 \mu$, and $\mathrm{I} .78 \mu$.

The effect of temperature and of intensity upon these maxima is illustrated in Figs. 14 to 17. 
Sample No. 2.-Curves $A$ and $B$, Fig. 8, show the photoelectric sensitivity of two regions of this sample. A small maximum appears at $\lambda=0.85 \mu$ and two maxima of about equal intensity at wave lengths $\lambda=0.99 \mu$ and $\mathrm{r} .85 \mu$, respectively.

Sample No. 3.-Curves $C$ and $D$, Fig. 8, illustrate the photoelectric behavior of two positions on this sample which appears similar to sample No. I. There are maxima at wave lengths $\lambda=0.73 \mu, \mathrm{r} .03 \mu$, and $\mathrm{x} .82 \mu$, respectively.

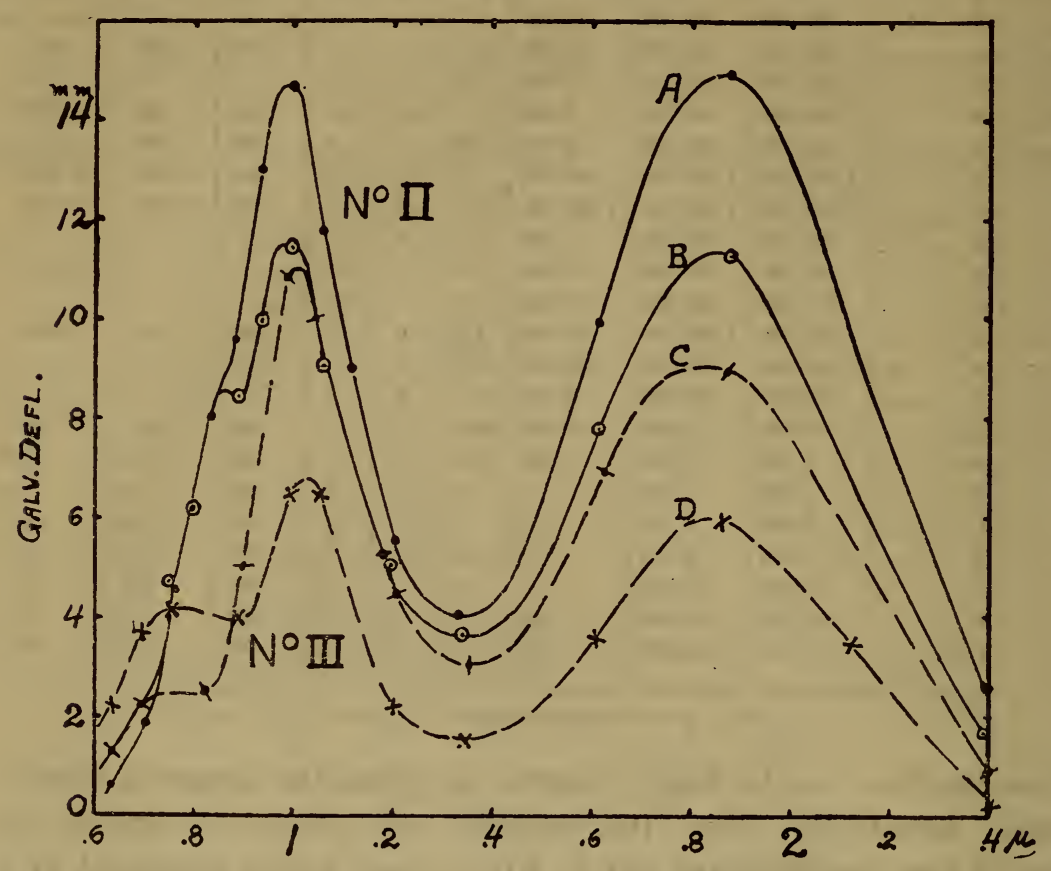

Frg. 8.-Photoelectric sensitivity of different parts of a crystal; also of different crystals

Sample No. 4.-This is the most remarkable sample examined in that at room temperature it has but one maximum, occurring at about $\lambda=0.85 \mu$; Fig. 9, curves $D$ and $E$, show the photoelectric behavior for two positions. The photoelectric sensitivity seemed to be confined to one small spot (see Fig. 19) for its behavior at low temperatures.

Sample No. 5.-Curves $A, B, C$, Fig. 9, illustrate the photoelectrical behavior of different parts of the surface. This sample is conspicuous for the absence of the first band usually observed at $\lambda=0.7 \mu$ to $0.8 \mu$ and for the greater intensity of the $1.85 \mu$ band as compared with the one at $\mathrm{I} \mu$. 
Sample No. 6.- In Fig. ro the lower curve shows the behavior of sample No. 6 , which is similar to No. 5 , with a possible small band at $\lambda=0.8 \mu$. The other maxima are at $1.02 \mu$ and $\mathrm{I} .85 \mu$.

The inserted diagram shows the important spots (indicated by shaded areas) of photoelectric sensitivity. The black dots represent points giving high rectification of current, which will be discussed presently.

Sample No. 7.- In Fig. ro curve $A$ illustrates the spectral photoelectric response of the central portion of sample No. 7. In

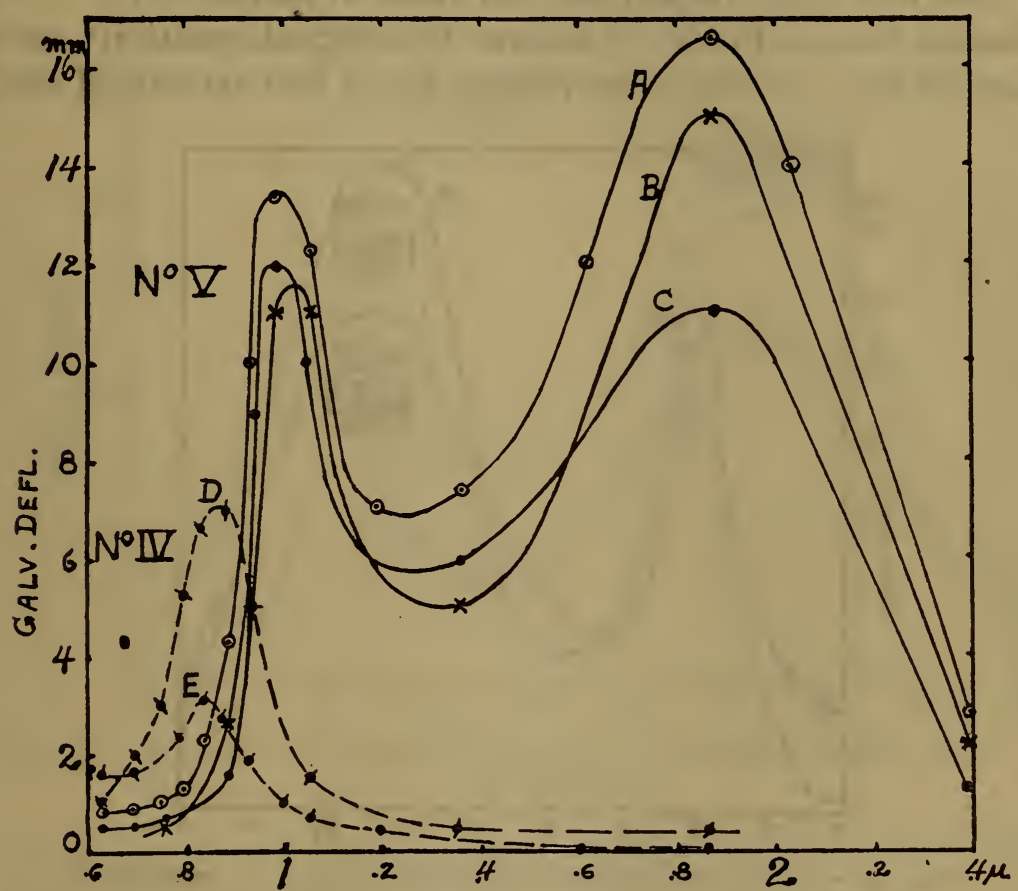

FIG. 9.-Photoelectric sensitivity of different parts of a crystal; also of different crystals

the upper rectangular diagram the shaded area represents the portion of the crystal which was photoelectrically sensitive, while the black dots represent points which showed high-current rectification. There are maxima at wave lengths $\lambda=0.85 \mu, \mathrm{r} .02 \mu$, and $\mathrm{r} .85 \mu$.

Sample No.8.-In Fig. I I the shaded portion of the rectangular diagram, marked $M o S_{2}$, represents the portion of the sample which was photoelectrically sensitive as determined with a photophone, the energy stimulus being about I $\mathrm{mm}$ in diameter. The 
image of the spectrometer slit (o.5 by ro $\mathrm{mm}$ ) was projected lengthwise, at the points marked $A, B, C, D$, and $E$ upon the crystal. The corresponding sensitivity curves are given in Figs. II and I2. These curves ( $C$ is incomplete) are interesting in that they show the gradual development of a maximum at wave length $\lambda=0.85 \mu$, belonging to a crystal aggregation in the center of the sample, which differs from the sensitive material along the lower edge of the crystal, curve $E$. The material along the lower edge of the crystal produced but two maxima, at wave lengths $\lambda=1.02 \mu$ and $1.85 \mu$, respectively, as found in sample No. 5 .

Sample No. 9.-In Fig. I 3 is given the spectral sensitivity curve of sample No. 9, which is conspicuous for its two maxima of equal

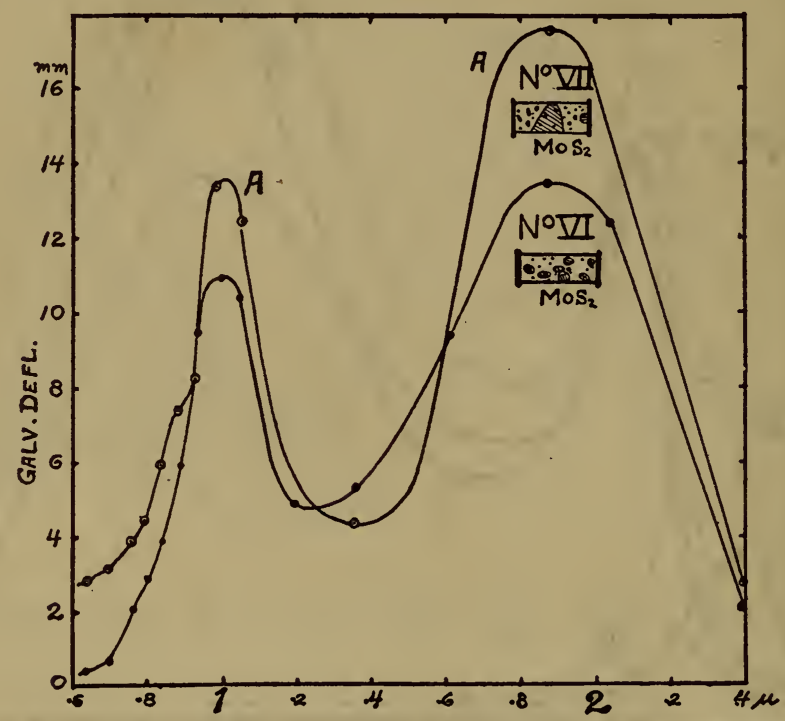

FrG. 10.-Photoelectric sensitivity of various crystals of molybdenite

intensity at wave lengths $\lambda=\mathrm{r} .02 \mu$ and $\mathrm{r} .85 \mu$, and a small maxima at $\lambda=0.85 \mu$.

Sample No. Io.-This sample was quite insensitive. However, an examination of two positions, curves $A$ and $B$, Fig. I3, shows a maximum sensitivity at wave length $\lambda=0.86 \mu$. It is sensitive also in the region of $\lambda=1.85 \mu$, as observed in other samples, especially No. 4 .

Sample No. II.-The dotted curve in Fig. I 2 gives the sensitivity curve of sample No. II, which, like No. 5 , is conspicuous for the absence of the band usually found at about $0.8 \mu$. The maxima of sensitivity are at wave lengths $\lambda=\mathrm{I} .02 \mu$ and $\mathrm{r} .85 \mu$, respectively. 
Samples No. I8, 20, and 22.-These samples were tested for sensitivity at the temperature of boiling liquid air where, as shown in Fig. 2I, they show sensitivity in the region of $\lambda=0.85 \mu$.

At room temperatures sample No. I 8 showed slight sensitivity (I to $2 \mathrm{~mm}$ deflection) in the spectrum from $0.6 \mu$ to $\mathrm{I} \mu$. Samples No. 20 and 22 were not sensitive even when exposed to radiation of much higher intensity.

The foregoing results show that at room temperatures the sensitivity maxima, at wave lengths $\lambda=\mathrm{I} .02 \mu$ and $\mathrm{I} .8 \mathrm{o} \mu$, respectively, always occur together. Some samples show an additional

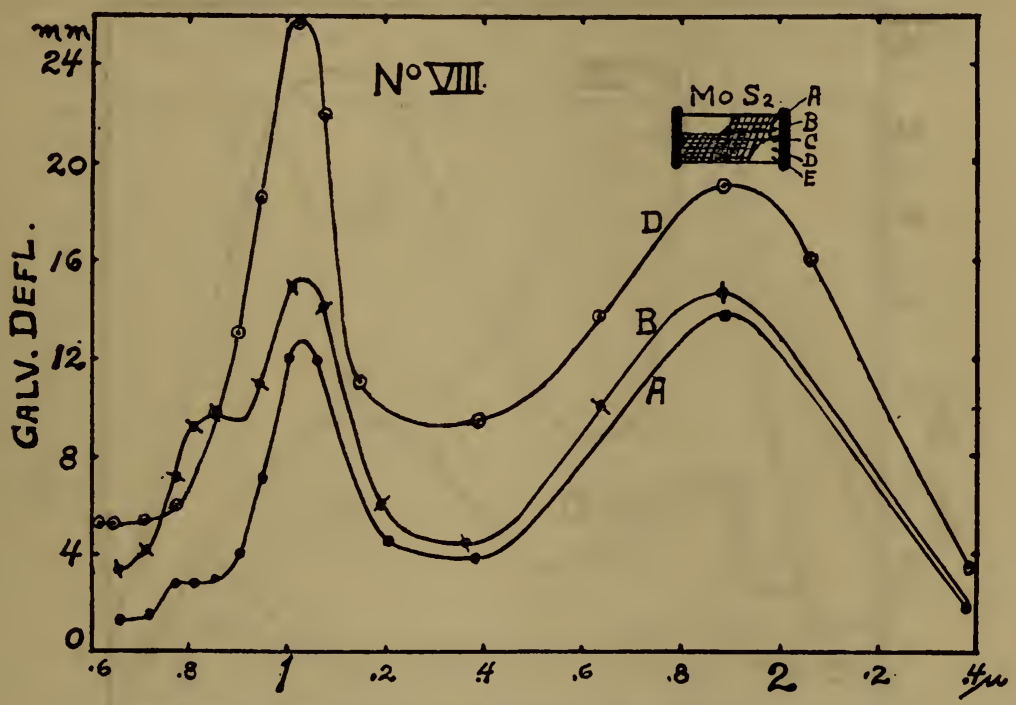
FIG. II.-Photoelectric sensitivity of different parts of molybdenite sample No. 8. (See

maximum at $\lambda=0.7 \mu$ to $0.85 \mu$. Other samples show only a single band of sensitivity at wave length $\lambda=0.85 \mu$.

\section{EFFECT OF INTENSITY OF RADIATION UPON ELEC- TRICAL CONDUCTIVITY}

Attempts have been made to formulate laws connecting the intensity (energy $E$ ) of the exciting light and the resulting change (galvanometer deflection) in conductivity of the selenium cell. In an investigation of the application of selenium to photometry Pfund ${ }^{25}$ points out that the final law will depend upon the character of the cell, time of exposure, and the absolute intensity of the exciting light. He made no attempt to establish a law for 
very intense or very weak illuminations. Using exposures of I 2.5 seconds, he found that the law connecting $d$ and $E$ to be approximately of the form $d=K E^{\beta}$ where $K$ and $\beta$ are constant as long as the wave length of the exciting light remains unchanged. The value of $\beta$ was approximately 0.5 , or the conductivity is approximately proportional to the square root of the energy stimulus.

In a subsequent investigation of the selenium cell, Nicholson, ${ }^{26}$ using unlimited exposures, found the square-root law to be only approximately true; that instead of the value of $\beta$ being

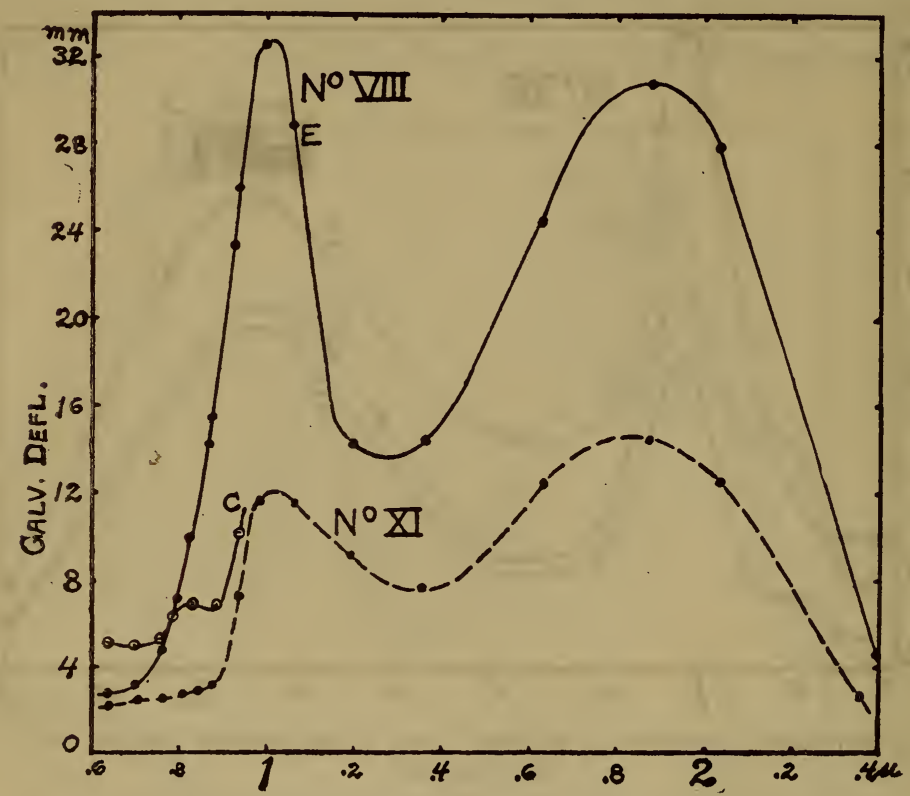

FIG. I2.-Photoelectric sensitivity of different parts of a crystal

constant there is an appreciable minimum at $\lambda=0.6 \mu$ where $\beta=0.4$. Spectral purity does not explain this disagreement.

Using exposures of ro seconds, Elliot ${ }^{27}$ investigated the law connecting the energy of the exciting light and the change in conductivity induced in stibnite. He assumed the square-root law to hold, and found that the values of $\beta$ did not prove the law. $\mathrm{He}$ argues that if unlimited exposures had been used it would be safe to say that the square-root law would hold for stibnite, and then concludes that stibnite obeys the law, with $\beta=0.5$, approximately. The conclusion to be drawn from the foregoing citation is that the experimental data do not indicate a simple 
square-root law, though for very rough calculations one might assume the law to obtain.

In view of the uncertainty of the experimental data just cited it was of interest to make similar tests of the effect of intensity of the exciting light upon the electrical conductivity of molybdenite at $22^{\circ} \mathrm{C}$.

For this purpose sample No. I was securely mounted in front of the spectrometer slit $S$, Fig. 2. The observations are illustrated in Fig. 14, in which curve $B$ gives the sensitivity for an intensity $E=20$, while curve $C$ shows the change in conductivity produced by an intensity $E=\mathrm{I}$. The latter intensity was obtained by covering the prism with a piece of black cardboard with a

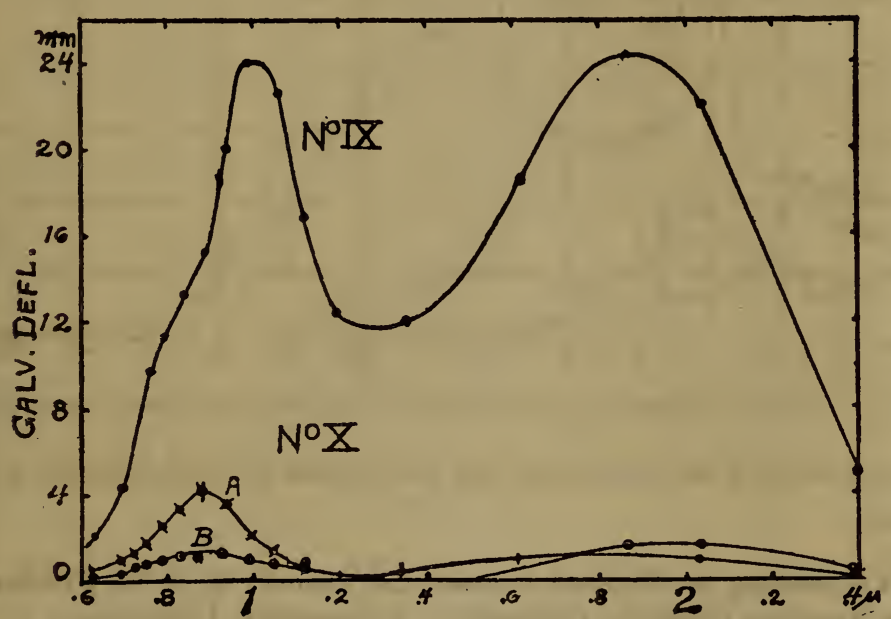

FIG. I3.-Photoelectric sensitivity of different crystals of molybdenite

slit in it, which happened to transmit almost exactly one-twentieth of the initial intensity. The results show that on increasing the intensity 20 times the spectral photoelectric responses are increased about ro times in the region up to $0.75 \mu$, I I times at $1.05 \mu$, and 20 times at $1.8 \mu$. In other words, on increasing the intensity 20 times the change in conductivity produced by energy of wave lengths $\lambda=1.8 \mu$ is twice as great as observed at $\lambda=0.75 \mu$. These energy stimuli are indicated by $E=\mathrm{I}$ and $E=20$ in Fig. I 5, which gives a series of isochromatic response curves for various wave lengths and for much higher intensities (40 times greater) than used in the investigation of the various samples just described.

In Fig. I 4 curve $A$ is for limited exposure and curve $B$ for exposure until a steady state is attained, as already described. 


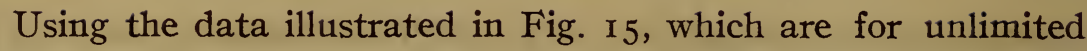
exposure (and are considered more accurate than those illustrated in Fig. 14), computations were made to test the validity of the square-root law. The computations show that (see Table 4) the induced change in electrical conductivity is not, as a general rule, proportional to the square root of the intensity (energy) of the radiation stimulus.

For example, selecting wave length $\lambda=0.6252 \mu$, using $E=2$ and $E=8$ (square root of ratio $=2$ ), the corresponding galvanometer deflections, $d$, are 4.4 and 9.8 , or a ratio of 2.23 instead

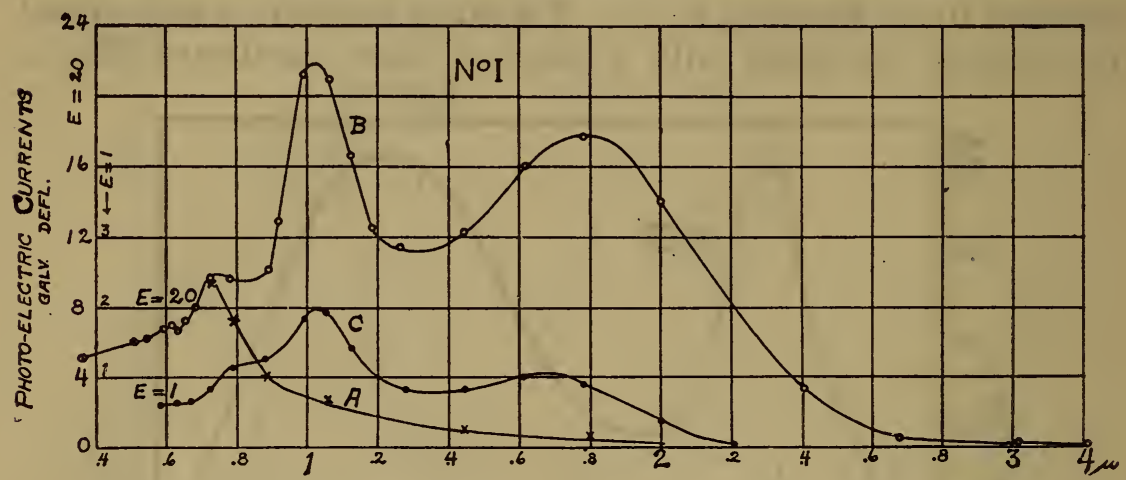

FIG. 14.-Effect of intensity of radiation upon spectral photoelectric sensitivity

of 2.0, as would be expected on the basis of the alleged squareroot law.

TABLE 4.--Showing the Relation Betwsen the Intensity $E$ of the Exciting Light and the Resulting Change in Conductivity, Galvanometer Deflection, $d$; $d=k E \beta$

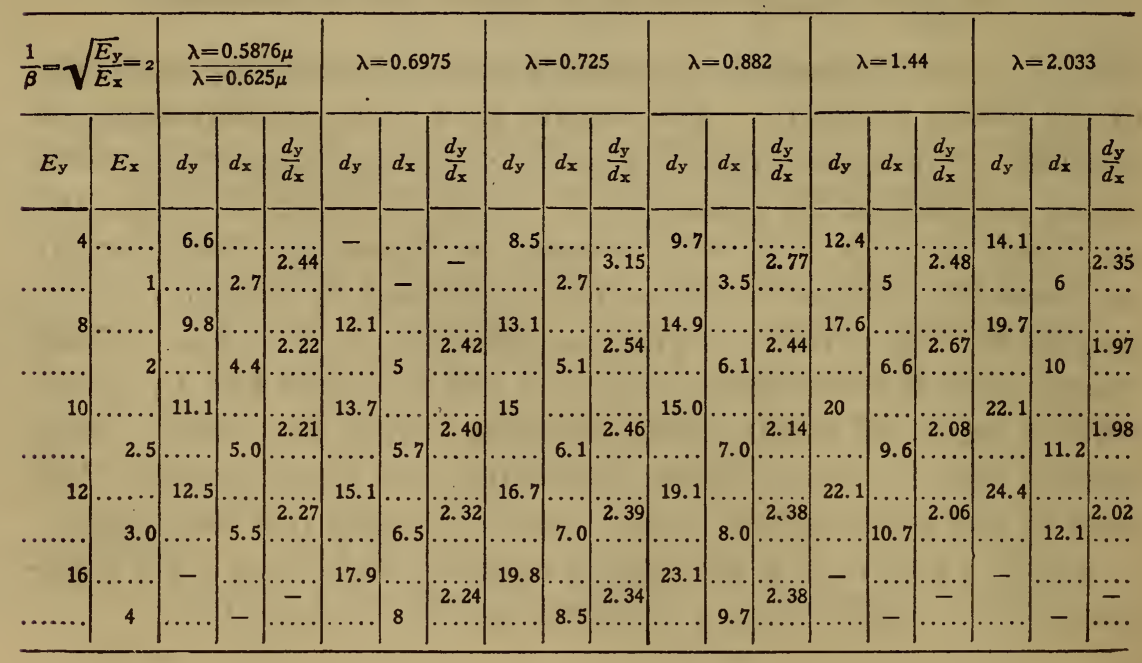


From the intensities used and the spectral range examined, it appears that at low intensities of the exciting radiation the change in electrical conductivity induced in molydenite is much greater than for higher intensities. For rough calculations the value of $\beta=0.43$ may be used.

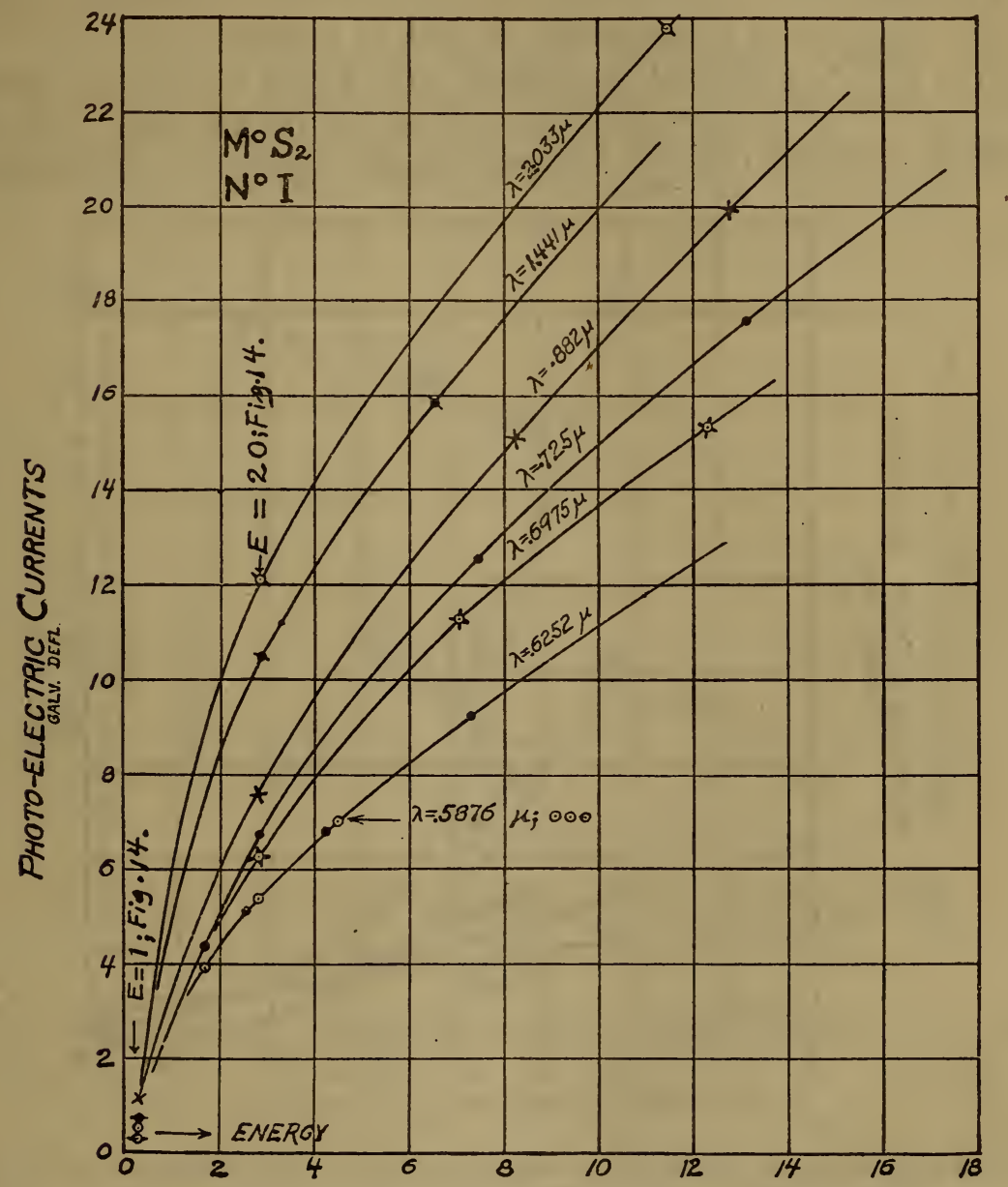

FIG. 15.-Effect of intensity of radiation upon photoelectric response

The data in Table 4 were obtained from Fig. ${ }_{5}$, in which the abscissa represents the energy, $E$, to which the molybdenite was exposed. Using even values of $E$ and four times its value (e. g., $E=4$ and $E=16$ ) the ratio of the corresponding galvanometer deflections, $d_{16} \div d_{4}$ should equal the whole number 2 if the squareroot law holds. An inspection of these columns of ratios $\left(\frac{d_{y}}{d_{x}}\right)$ for different wave lengths, shows that the value $\beta$ depends upon the wave length as well as the intensity of the exciting radiations. 


\section{EFFECT OF TEMPERATURE ON PHOTOELECTRIC SEN- SITIVITY}

An interesting part of this investigation was the determination of the effect of temperature on photoelectrical conductivity. The electrical conductivity of molybdenite decreases rapidly with decrease in temperature, so that at a temperature of $-140^{\circ}$ to $-178^{\circ} \mathrm{C}$ (attained by cooling. with liquid air) the resistance is 150 to 2000 times as great as at room temperature. On the other hand, at this low temperature the change in conductivity

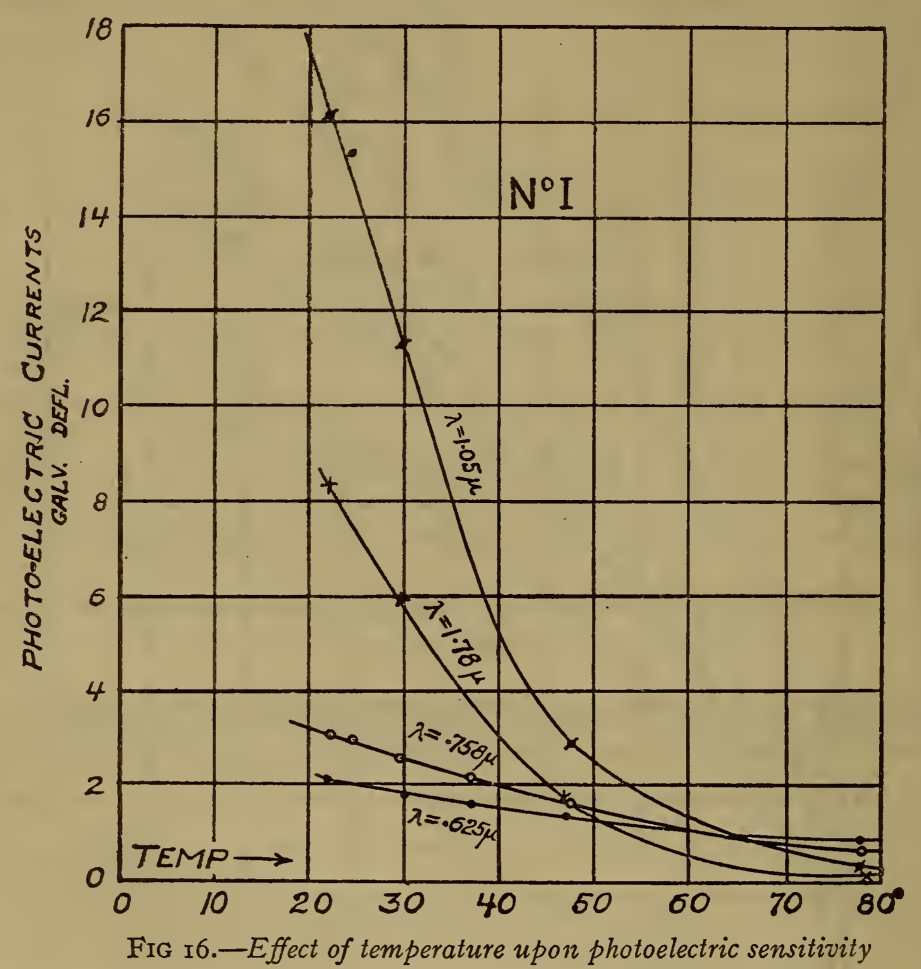

induced in some samples of molybdenite, when exposed to radiation of certain wave lengths, is from 50 to 200 times as great as at room temperatures. This comparison was obtained by increasing the voltage applied to the sample, at liquid-air temperature, to produce practically the same dark current (galvanometer deflection of 60 to $85 \mathrm{~cm}$ ) as obtained when the sample was operated at room temperature. In practice the samples were operated on 2 to 4 volts at room temperature and on 40 to 133 volts (dry cells) at liquid-air temperatures. The dark currents were noted and a factor was applied to indicate the deflection that 
would have been obtained if the sample had shown the same dark current at these two temperatures. This does not affect the relative spectral sensitivity curves, but merely gives the reader some idea of the size of the deflections that would be expected when the crystal was examined under comparable conditions.

Sample No. I.-In one test the molybdenite sample No. I was mounted in a small wooden box containing a thermometer and a thin strip of platinum heated by a storage battery. A rocksalt window permitted exposure to radiation. The sample was mounted at the exit spectrometer slit. As shown in Fig. I6, using

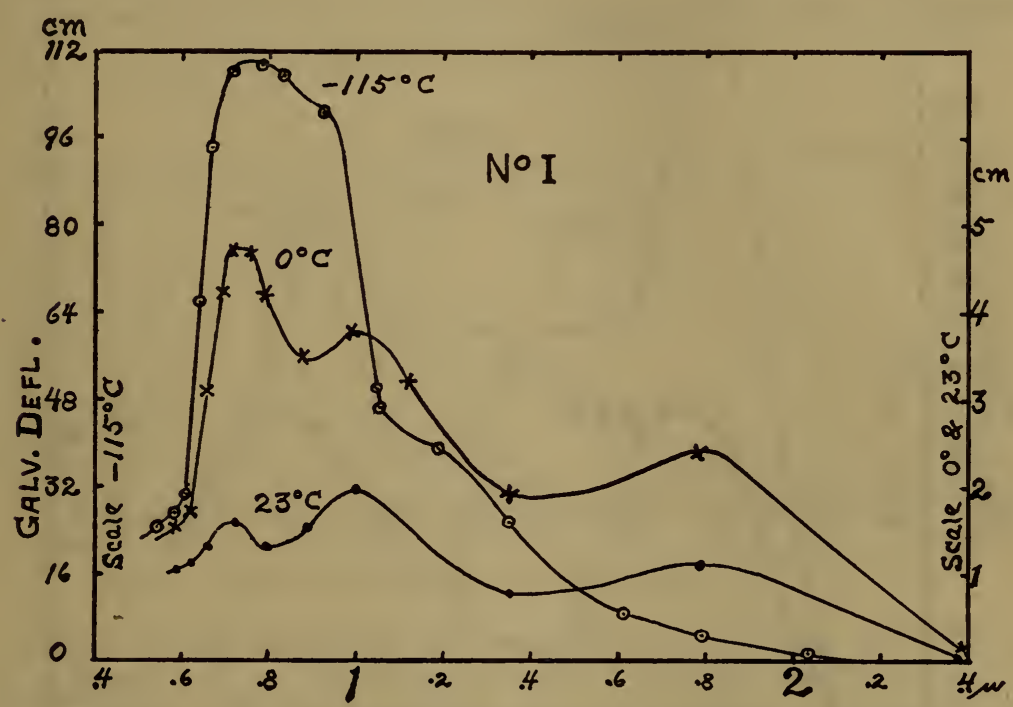

FIG. 17.-Effect of temperature upon spectral photoelectric sensitivity

the same intensity (applied voltage, 2 volts) and varying the temperature of the sample, it was found that the maxima at $\lambda=\mathrm{I} .5 \mu$ and $\mathrm{I} .78 \mu$ decreased very rapidly in intensity, so that at $80^{\circ} \mathrm{C}$ the photoelectric action produced by radiations of these wave lengths had practically disappeared, whereas the radiations of short-wave lengths still produced a change in electrical conductivity.

In the following tests the sample was mounted in the glass receptacle illustrated in Fig. 2 and the temperature changed as already described. In Fig. I 7 is illustrated the change in photoelectric sensitivity of sample No. I when operated at $23^{\circ} \mathrm{C}$, $0^{\circ} \mathrm{C}$, and $-\operatorname{II} 5^{\circ} \mathrm{C}$. For the latter temperature the observed galvanometer deflections (maximum $=16 \mathrm{~cm}$ ) were multiplied 
by the factor 8 , in order to show the approximate sizes of the deflection to be expected for the same dark current. The potential actually applied was io volts.

At $\mathrm{o}^{\circ} \mathrm{C}$, sample No. I on 2 volts gave a (dark-current) galvanometer deflection of $43 \mathrm{~cm}$ and on 4 volts a deflection of 86 $\mathrm{cm}$. Using radiations of $\lambda=0.724 \mu$, the corresponding (photoelectric) galvanometer deflections were 23.5 and $47 \mathrm{~mm}$, respectively, indicating a close proportionality between the dark current and the photoelectric current.

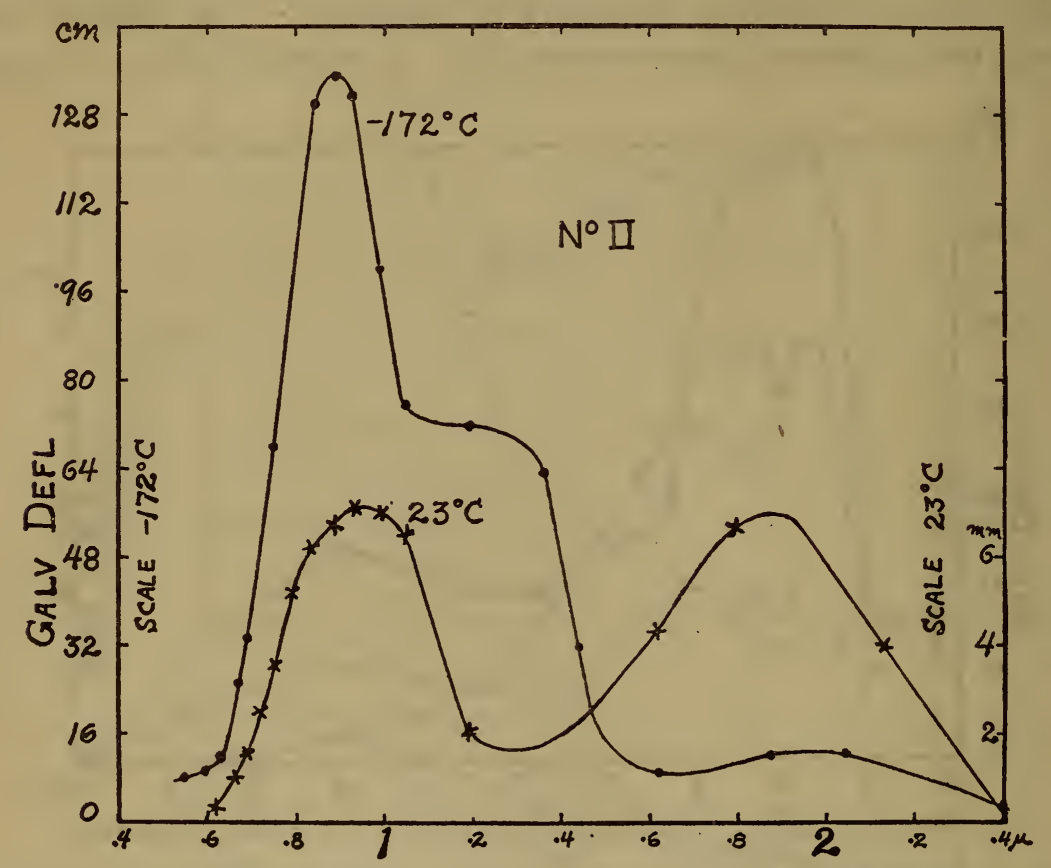

FIG. 18.-Effect of temperature upon spectral photoelectric sensitivity

These curves show that as the temperature decreases the radiations of short-wave lengths produce a greater change in electrical conductivity than do the long-wave lengths. As a result, the maximum of the sensitivity curve is shifted from $\lambda=\mathrm{I} .02 \mu$ to $\lambda=0.75 \mu$. A new band occurs at $\lambda=\mathrm{I} .2 \mu$.

Sample No. 2.- In Fig. I 8 are given the photoelectric sensitivity curves of sample No. 2 at $23^{\circ} \mathrm{C}$ and $-172^{\circ} \mathrm{C}$, respectively. In the latter the scale of deflections is magnified 8 times, to represent equal dark-current conditions. The voltage applied at $-172^{\circ} \mathrm{C}$ was 133 volts. The maximum of the sensitivity curve is shifted to the short wave lengths, the maxima being at $\lambda=0.88 \mu, \mathrm{I} .20 \mu$, and $I .9 \mu$, respectively. 
Sample No. 4.-The effect of temperature upon the photoelectric conductivity of sample No. 4 is shown in Fig. 19. The observations at $25^{\circ} \mathrm{C}$ confirm the measurements made some months earlier, curves $D$ and $E$, Fig. 9. At $-178^{\circ} \mathrm{C}$ the maximum appears to be shifted slightly to the longer wave lengths, $\lambda=0.89 \mu$, and a second band appears at $\lambda=1.23 \mu$. The observed galvanometer deflections ( $2 \mathrm{~cm}$ at $\lambda=1.23 \mu$ ) are multiplied by the factor 25 , to indicate the deflections to be expected for the same dark current, at these two temperatures. The deflections being so small it is uncertain whether the $1.23 \mu$ band is present at room temperature. At $-178^{\circ} \mathrm{C}$ this sample was practically nonconducting, and $\mathrm{r} 33$ volts were applied in making the examination, as against 2 volts at room temperature.

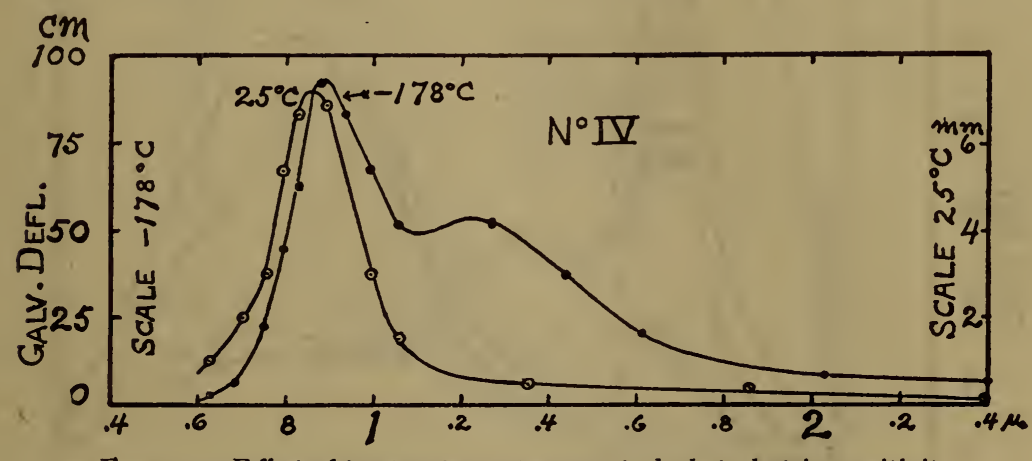

FIG. I9.-Effect of temperature upon spectral photoelectric sensitivity

Sample No. 5.-In Fig. 20 are given a series of photoelectric conductivity curves of sample No. 5, which was mounted as shown in Fig. 2 and observed under similar conditions. The temperature points $38^{\circ} \mathrm{C}, 26^{\circ} \mathrm{C}, 0^{\circ} \mathrm{C}$, and $-142^{\circ} \mathrm{C}$ were obtained by means of hot water, ice, and liquid air, as already explained. The potentials applied were 2 volts at $38^{\circ} \mathrm{C}$ and $26^{\circ} \mathrm{C}, 4$ volts at $0^{\circ} \mathrm{C}$, and 40 volts at $142^{\circ} \mathrm{C}$. The observed galvanometer deflections are given in Fig. 20. In order to make the observations comparable (for the same dark current), the galvanometer deflections for $0^{\circ} \mathrm{C}$ would be $\mathrm{I} 7$ times greater than plotted in Fig. 20.

These data are of interest in showing the rapid shift of the maximum sensitivity toward the short wave lengths, with decrease in temperature. At $-142^{\circ} \mathrm{C}$ there are maxima at $\lambda=0.88 \mu, \mathrm{r} .35 \mu$, and $\mathrm{r} .9 \mu$, respectively, as compared with two maxima at $\lambda=1.02 \mu$ and $\mathrm{I} .9 \mu$, respectively, at room temperatures. 
In view of the long time required in order to obtain the data at $1.8 \mu$, the irregularities in the relative intensities and in the position of the maximum are probably to be attributed to experimental errors.

Sample No. I8.-National Museum specimen No. 61448, from Shirakawa Hidi, Japan. This material had a low resistance and a low photoelectrical conductivity at room temperatures. At liquid-air temperatures, $-178^{\circ} \mathrm{C}$, this sample shows a band of

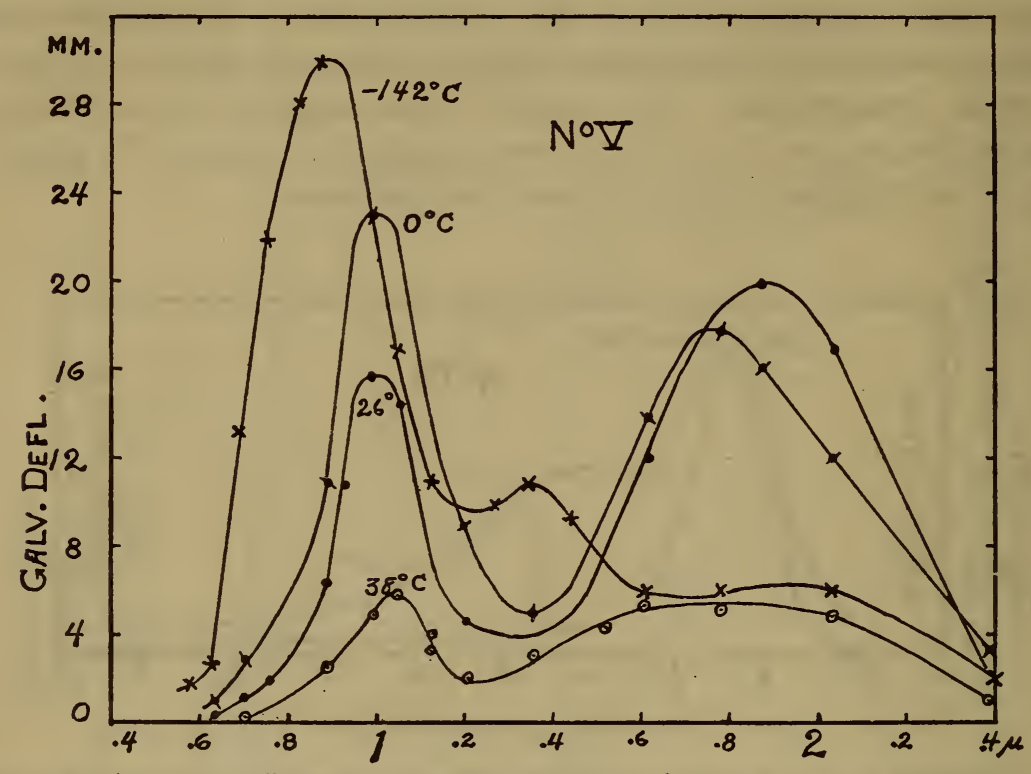

FIG. 20.-Effect of temperature upon spectral photoelectric sensitivity

photoelectrical sensitivity with a maximum at $\lambda=0.85 \mu$. (See Fig. 2I.)

Sample No. 20.-National Museum specimen No. 53046, from Wakefield, Canada. Transmission and reflection measurements were also made on this material, which has a low photoelectric conductivity even at low temperatures, at $-177^{\circ} \mathrm{C}$. There is a single maximum at wave length $\lambda=0.85 \mu$ (lower curve of Fig. 2I).

Sample No. 22.-National Museum specimen No. 86194, from near Chilcoot Pass, Alaska. This material has a low resistance and low photoelectric sensitivity at room temperatures. At $-178^{\circ} \mathrm{C}$ this material shows a wide band of spectral photoelectric sensitivity, with a maximum at wave length $\lambda=0.85 \mu$. (Fig. 2I).

A general survey of these curves shows that samples of molybdenite which show but small photoelectrical sensitivity at room temperatures exhibit considerable photoelectrical conductivity at 
the temperature of boiling liquid air. This, of course, is to be expected in view of what was observed on samples which are quite sensitive at ordinary temperatures. The comparison is one of magnitude of photoelectrical sensitivity rather than one of quality. For at low temperatures, where all samples exhibit sufficient photoelectrical sensitivity to make the tests trustworthy, the maximum photoelectrical conductivity of samples from different localities is produced by radiations of wave lengths in the spectrum at $\lambda=0.85 \mu$. As already mentioned, Crandall ${ }^{28}$ records observations made by Trowbridge which show that the transparency of molybdenite is considerably increased in the visible

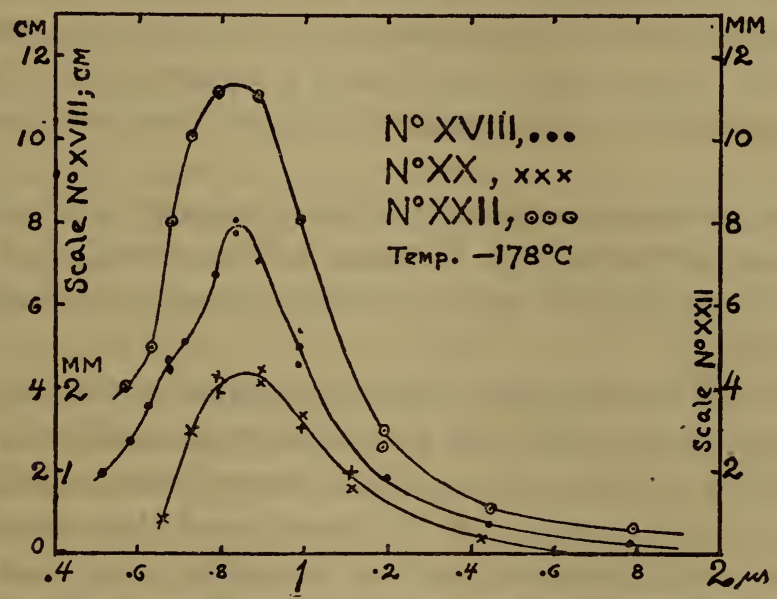

FIG. 21.-Effect of temperature upon spectral photoelectric sensitivity

spectrum when the material is cooled to liquid-air temperature. Just what this has to do with a similar shift of the maximum of the photo electric sensitivity curve toward the visible spectrum is not known. That such a shift occurs appears to be an established fact. That the greatest photoelectrical activity occurs where the absorption is low, and that this region of maximum activity shifts toward the region of maximum absorption, is worthy of notice even though no explanation is offered to account for the observations.

\section{EFFECT OF HUMIDITY, VACUUM, AND MECHANICAL WORKING}

In the early part of this investigation the question arose as to the effect of humidity on the photoelectrical conductivtiy of molybdenite. The test was made in an air-tight glass receptacle 
which replaced the glass tube $G$, Fig. 2. Provision was made to introduce phosphorus pentoxide into the vessel and sealing it without disturbing the adjustments. An interval of four hours elapsed after introducing the dehydrating material. The observations were made at $25^{\circ} \mathrm{C}$ with the humidity of the surrounding air amounting to $8 \mathrm{I}$ per cent or $12 . \mathrm{I} \mathrm{g}$ per cubic meter.

The results obtained show that this amount of moisture had no observable effect upon the photoelectrical conductivity.

Observations of the effect of air upon photoelectrical change in conductivity were made, using the sample in the glass receptacle $G$, Fig. 2. Keeping the temperature constant, the results obtained with the molybdenite in air and a vacuum show that the spectral photoelectric sensitivity curve was not affected by the surrounding air. Recent experiments of Tisdale ${ }^{29}$ indicate that the photoelectric conductivity of selenium is affected by gases and metallic vapors.

The conclusion arrived at is that the photoelectrical conductivity observed in molybdenite is inherent in the crystal, and that this property is not affected by the ordinary changes in humidity and gas pressure.

One line of investigation which requires further attention is the effect produced upon the photoelectrical sensitivity when the surface of the molybdenite sample is worked mechanically.

In a previous investigation ${ }^{30}$ it was found that silver sulphide which had been prepared in the laboratory and subjected to rolling and hammering was not very sensitive photo-electrically. On the other hand, a sample of the natural mineral, acanthite $\mathrm{Ag}_{2} \mathrm{~S}$, was rendered photoelectrically insensitive by hammering the crystals into a flat plate. Furthermore, in this preliminary work there was evidence that samples of molybdenite were photoelectrically less sensitive after rubbing and polishing the lamina.

In the present tests the sample was soldered to No. 26 copperwire electrodes (see Fig. Io) and a sensitive spot was located by means of the radiophone. This photoelectrically sensitive spot was then pressed and rubbed with a smooth, flat, wooden toothpick. On reexamination (using a radiophone), the spot was found less sensitive photoelectrically than it was before subjecting it to pressure. No material having been removed in the process of rubbing and smoothing the surface, it would appear that destruction of crystal structure may have something to do with the change 
in photoelectric sensitivity. Sometimes laminæ of molybdenite are found which contain pockets of fine crystalline material, and it is not unreasonable to suppose that crystals of microscopic size are included in the regular lamina.

\section{PHOTOELECTRIC SENSITIVITY VERSUS CURRENT RECTIFICATION}

In the course of this investigation it was observed, as already mentioned, that samples of molybdenite which are photoelectrically sensitive have a considerably higher electrical resistance (see Table 3 ) than samples which are not sensitive to light. Moreover, the conductivity of the insensitive samples was found to be quite independent of the direction in which the current passed (lengthwise) through the crystal.

On the other hand, samples of molybdenite which are sensitive photoelectrically were found to possess a much higher conductivity when the electric current (from a 4-volt battery) was passed in one direction than when it was passed in the opposite direction through the crystal. As shown in Table 3, this difference in current leakage (dark current), as dependent upon the direction of the current through the crystal, varied from io to 30 per cent for different crystals. In observing the foregoing sensitivity curves, the photoelectric current was therefore proportionately increased by connecting the crystal into the battery circuit in the proper direction to obtain the maximum change in photoelectric conductivity.

In view of these observations it was of interest to determine whether there is any connection between photoelectric sensitivity and the rectifying action which occurs when the crystal is placed in a high frequency oscillating circuit. ${ }^{31}$

For this purpose crystals (size ro by 4 by o.I $\mathrm{mm}$ ) were selected which showed one or two small photoelectrically sensitive spots, but which were quite insensitive throughout the remainder of the surface of the crystal.

These sensitive spots were mapped by projecting a spot of light upon the sample, the change in conductivity being detected by means of the radiophonic apparatus described elsewhere in this paper. In Figs. Io and I I the rectangular areas represent the sample soldered to copper-wire electrodes. The photoelectrically sensitive spots are represented by the cross-hatched areas.

31 These data were obtained in collaboration with Dr. Louise S. McDowell and reported upon at the meeting of the American Phys. Soc., December, r9r8; Phys. Rev., 13, p. 154, r919. 
The rectification tests were made by means of an ordinarytuned buzzer circuit. The telephone and detector, in series, were placed in parallel with the condenser of the secondary circuit. The coupling was adjusted to produce strong oscillations in the secondary circuit.

The molybdenite crystal was explored for rectification by touching the surface by means of a fine metal point. In Figs. ro and I I the dark points in the rectangular areas represent spots showing current rectification, the size of the spot representing the magnitude of the effect observed.

The results of these tests show that the low-resistance, photoelectrically insensitive samples of molybdenite are far more efficient rectifiers than the high-resistance light-sensitive specimens. One specimen which showed no photoelectric sensitiveness $_{\mathrm{f}}$ whatever, as determined by a sensitive galvanometer, produced decided rectification over almost its entire surface. In fact, it was difficult to find a spot which produced no rectification. On the other hand, the samples of molybdenite having a high resistance exhibited the rectifying action only in spots, which usually did not coincide with the photoelectrically sensitive spots. These radioelectrically sensitive spots were widely scattered over the surface, but sometimes comparatively large areas were found which showed no electrical rectification, as indicated by the telephone. Only the most sensitive spots of the highresistance material produced a rectification approaching that of the specimens having a low resistance.

In two instances especially electrically sensitive spots were found upon the light-sensitive areas (see Fig. ro, No. VII), but other equally sensitive spots occurred in the areas which were photoelectrically insensitive. This test alone would seem to be sufficient to prove that the two phenomena are not intimately connected.

The conclusions to be drawn are, therefore, that (I) the lowresistance, photoelectrically insensitive molybdenite exhibits much greater rectifying action than the high-resistance photoelectrically sensitive specimens; (2) there is no apparent relation between the electrical rectification and the photoelectric change in conductivity observed in molybdenite. 


\section{EXUDATION OF A DARK-BLUE LIQUID}

One of the numerous questions requiring further investigation is the exudation of a dark-blue liquid from some samples of molybdenite. At the beginning of this inyestigation it was found that some samples became a black amorphous mass in spots when electric current was passed through them. The behavior of one sample deserves description. In making the preliminary sensitivity tests this sample was clamped between heavy brass electrodes and tested for local sensitivity, using an audion amplifier and telephone receiver. It was found that one end of this sample, close to the electrode, was unusually sensitive, causing a loud note to be emitted by the telephone receiver. On examination a bubble of liquid was found in violent ebullition. Exposure of this bubble to light produced a change in electric current and hence a sound in the telephone receiver. Other samples were found which became dark masses in spots which did not appear to be markedly sensitive photoelectrically.

The presence of a dark-blue liquid (probably the "blue oxide" described by Guichard ${ }^{32}$ ) on a surface of a molybdenite detector is mentioned by Huizinga ${ }^{32}$. According to Guichard the blue oxide of molybdenum is a colloid which is extremely soluble in water.

In view of the foregoing experiments, further tests were made on the production and the photoelectric sensitivity of this dark substance. In order to produce this dark substance, the end of a thin platinum wire was placed in contact with the surface of a sample of molybdenite, and this combination was joined in series with a dry battery of ro to 75 volts and an audion amplifier. It was found that a black viscous mass was formed on the highresistance, photoelectrically sensitive samples, but no blackening of the surface occurred at the point of contact of the platinum wire with the surface of samples of molybdenite which had a low resistance. This black substance, which indicated an acid reaction when tested with litimus paper, was formed irrespective of the direction of the electric current. Tested with an iron-constantan thermocouple of fine wires, the temperature rise at the point of contact of the platinum wire with the molybdenite was the higher for the low-resistance material. It would, therefore, seem that this is not a phenomenon resulting alone from a high tempera-

\footnotetext{
${ }^{32}$ Guichard, Ann. Chimie et Physique (7), 23, p. 5r9, Igor; Huizinga, Proc. K. Akad. Amsterdam, 19, p. 512,1917 .
} 
ture. This blue substance becomes hard and brittle on breaking the electric circuit and is easily removed by touching the surface with a bit of cotton moistened with water.

For the photoelectric test a spot of thin, dark substance, about $3 \mathrm{~mm}$ in diameter, was formed surrounding the point of contact of the platinum point with the surface of a sample of molybdenite of average photoelectric sensitivity. Light of high intensity passing through the rotating sectored disk was projected upon this viscous, bubbling substance. Sensitivity tests were made before the formation of this substance, also during its formation, and again after its removal. The results showed that, if anything, the presence of this substance decreased the photoelectric sensitivity of the sample. In other words, this blue oxide does not appear to be sensitive photoelectrically.

A further observation worth mentioning is that the bunsenflame spectrum of molybdenite shows more sodium in the photoelectrically sensitive samples than in the nonsensitive material. Evidently this whole subject needs further investigation.

\section{THEORETICAL APPLICATIONS}

It is of interest to notice the bearing of the foregoing data upon theories of photoelectrical conduction. Pfund ${ }^{33}$ has proposed a theory based on electronic conduction, the electrons being set free by the incident radiations. Among others, he has sought a connection between optical absorption and photoelectrical activity. $\mathrm{He}$ avoids the apparent inconsistency of greatest photoelectrical activity in the region of the spectrum where the absorption is the least by assuming a critical thickness at which change of resistance sets in. In the region of greatest absorption the rays do not penetrate deeply and the current-carrying layer is less than this critical thickness. In the more transparent regions of the spectrum the depth of penetration is greater; the current-carrying layer becomes greater than the critical thickness and hence a greater change in conductivity is possible. It is assumed that the light is effective in producing changes in resistance only until the amplitude has decreased to a certain minimum value, below which its effectiveness is lost. This agrees with the resonance theory, since no electrons are expelled from the atom until the amplitude due to resonance exceeds a definite minimum value. 
On the basis that the maximum of sensitivity depends upon the depth of penetration of light, increasing the intensity, and therefore the penetration, should cause a shift of the maximum toward the shorter wave lengths. Pfund's tests seemed to show this, though in a subsequent investigation ${ }^{34}$ he publishes a series of curves, which might be interpreted to show, as found in the present investigation, that with increase in intensity the region of maximum photoelectrical activity shifts towald the infra-red and the sharp bands increase most rapidly on the long wavelength side, with increase in intensity.

Another theory is based upon evidence ${ }^{85}$ that there are several forms of material (selenium) differing widely in resistivity, and that the action of radiation is to transform the less conducting material into one having greater conductivity. For selenium, Brown ${ }^{36}$ assumes the existence of three forms, and in subsequent investigations has formed a large number of crystals by sublimation of the material in an electrically heated oven. ${ }^{37}$

In the present paper no attempt is made to harmonize the observations with these theories. In this connection, however, it is of interest to note that there are several sulphur compounds of molybdenum, $\mathrm{Mo}_{2} \mathrm{~S}_{3}, \mathrm{MoS}_{4}, \mathrm{MoS}_{3}$, and $\mathrm{MoS}_{2}{ }^{38}$ which have been made artificially. The question naturally arises as to whether these observed bands of spectral photoelectrical sensitivity are connected with small inclusions of some of these sulphur compounds. The experimental data might lead one to infer that there are several forms present, causing characteristic bands of photoelectric sensitivity. For example, the bands of photoelectric sensitivity at $\lambda=1.02 \mu$ and $\mathrm{r} .85 \mu$ always occur together. Some samples of molybdenite show an additional maximum at $\lambda=0.75 \mu$ or $0.85 \mu$, while another sample, No. 4 , shows only a single band at $\lambda=0.85 \mu$. It is planned, therefore, to test the spectral photoelectrical sensitivity of artificial sulphur-compounds of molybdenum.

The observation of a series of maxima of photoelectric sensitivity is so novel, and the data at hand are so meager, that it is rather hazardous to attempt to discuss their theoretical bearing. If we had plotted frequencies, instead of wave lengths, it would be evident that these maxima are separated by equal intervals. This

${ }^{34}$ Pfund, Phys. Rev., 34, p. 370; 1912.

35 Marc. Die Phys. and Chem. Eigensch. Metallsches Selens, r909; Uljanin, Wied. Ann., 34, p. 24 r, r888.

${ }^{36}$ Brown, Phys. Rev., 32, pp. 237 and 252; 33, p. r, 1911.

${ }^{37}$ Brown, Phys. Rev. (2), 4, p. 85, 1914.

28 Guichard, Ann. Chim. et Physique (7), 23, p. 498, rgor. 
is illustrated in Fig. 22, where the data given in Fig. I 7 are plotted, the abscissae being the reciprocals of the wave lengths

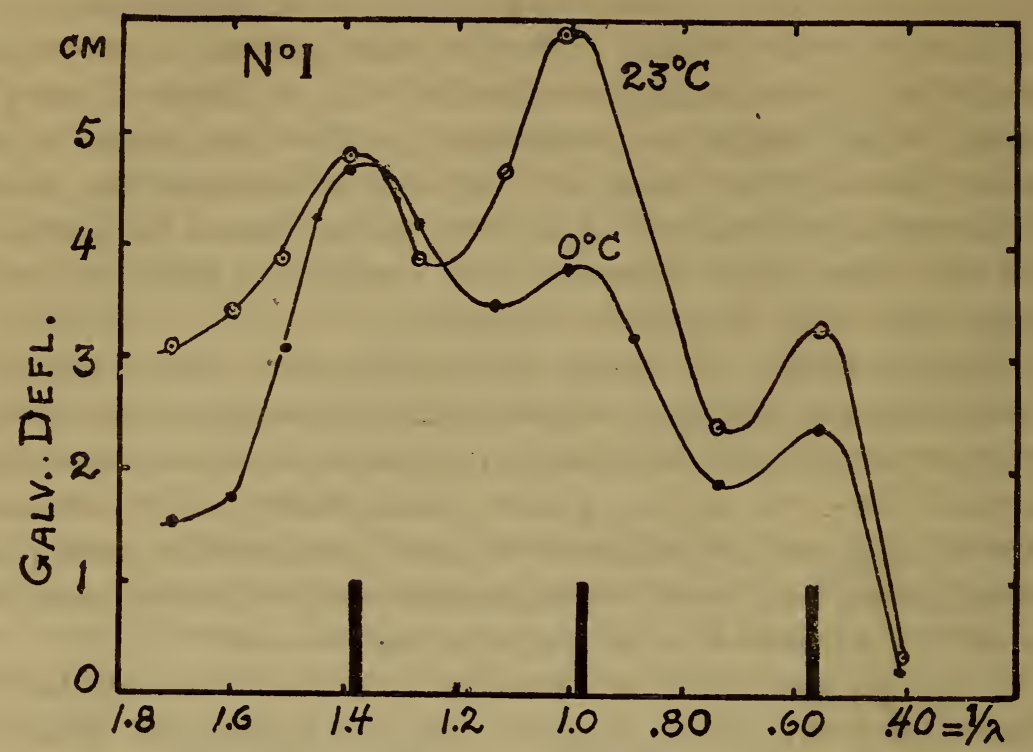

FIG 22:- Spectral photoelectric sensitivity plotted against frequency instead of wave length of the radiation stimulus

(in $\mu=0.001 \mathrm{~mm}$ ). The ordinates of the curve for $23^{\circ} \mathrm{C}$ are magnified three times, in order to facilitate comparsion.

TABLE 5.-Maxima of Photoelectric Sensitivity and the Wave Number, $n$, or Common Difference Between the Reciprocals of these Wave Lengths

\begin{tabular}{|c|c|}
\hline Sample- & Sample- \\
\hline 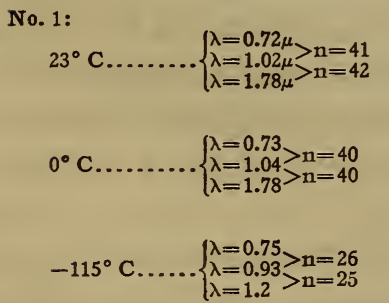 & 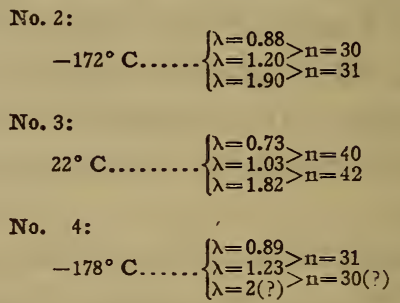 \\
\hline
\end{tabular}

As shown in Table 5 , the difference in the frequency maxima or wave number is $n=40$ for room temperature; while at low temperatures it is $n=25$ in some cases and $n=30$, just as though there were several kinds of crystals present. The data on samples No. 2 and 
No. 4 would seem to indicate, as already noted, that the great variation in photoelectric sensitivity seems to be one of degree of sensitivity and not one of quality.

It is to be noted that the spectral lines represent an emission of thermal radiation as the result of (electrical) excitation of gas ions or electrons, whereas in the present case thermal radiations of certain frequencies produce marked changes in the electrical conductivity of the substance. On the resonance theory one would be led to expect fundamental and harmonic frequencies which are capable of producing marked changes in electrical conductivity. On this basis one would expect to find additional harmonic bands, which for sample No. I should occur at $\lambda=0.56 \mu$ and $\lambda=6.5 \mu$. As a matter of fact this sample is quite sensitive in the visible spectrum (see Fig. 14), but this question was not foreseen and the energy calibration was not sufficiently accurate to establish a maximum at this wave length.

Before discussing the data more closely, it will be desirable to make a further examination of these samples, using a very much larger dispersion, which will give greater purity of the radiation stimulus in the region of $0.6 \mu$ to $\mathrm{r} .2 \mu$. As matters now stand, it is not apparent, in some cases, why the band at $0.72 \mu$ is absent if it is harmonic with the bands at $1.02 \mu$ and $1.78 \mu$.

\section{SUMMARY}

The present paper gives data on the change in the electrical conductivity of molybdenite when exposed to thermal radiations of wave lengths extending from wave length $\lambda=0.36 \mu$ in the ultraviolet to beyond $\lambda=9 \mu$ in the infra-red.

The radiations of wave lengths extending from the ultra-violet to about $3 \mu$ produce a change in the electrical conductivity of molybdenite. The effect of temperature, humidity, intensity of the exciting light, etc., upon the photoelectrical sensitivity of molybdenite was investigated. Atmospheric humidity does not appear to affect the shape of the spectral photoelectric sensitivity curve.

The effect of increasing the intensity of the exciting radiations appears to be to produce a more rapid response in the long wave lengths than in the short wave lengths, with a resultant shift of the spectral photoelectric sensitivity curve toward the long wave lengths.

There is no simple law governing the variation in the photoelectric response in molybdenite, with variation in intensity of the radiation stimulus. 
At room temperatures there are maxima of sensitivity in the region of $\lambda=0.7 \mu, 0.85 \mu, \mathrm{I} .02 \mu$, and $\mathrm{r} .8 \mu$. Beyond $2.5 \mu$ the photoelectric sensitivity is practically nil.

Raising the temperature causes a rapid decrease in the spectral photoelectric sensitivity, especially in the regions of $\mathrm{r} .02 \mu$ to I. $8 \mu$. At $80^{\circ} \mathrm{C}$. the spectral photoelectric sensitivity has practically disappeared, only slight indications being observed for radiations of wave lengths $\lambda=0.6 \mu$ to $0.8 \mu$.

The effect produced by lowering the temperature is to greatly increase the sensitivity curve throughout the whole spectrum from the ultra-violet to $2.5 \mu$ in the infra-red. This increase in sensitivity is greatest in the region of $0.8 \mu$ to $0.9 \mu$, so that at the temperature of boiling liquid air the maximum sensitivity occurs at about $0.85 \mu$, with a new band at $1.25 \mu$ to $1.35 \mu$. Samples of molybdenite which are quite insensitive at room temperatures become fairly sensitive, photoelectrically, at $-\mathrm{r} 78^{\circ} \mathrm{C}$. At low temperatures the spectral photoelectric sensitivity curves of all samples are quite similar, with a maximum in the region of $0.8 \mu$ to $0.9 \mu$. From this it would appear that this photoelectric property is one of degree rather than one of quality. The fact that the bands at $\mathrm{r} .02 \mu$ and $\mathrm{r} .8 \mu$ occur together, and that the $0.85 \mu$ band may occur alone suggests the possibility that they are characteristic bands of spectral photoelectric sensitivity of different sulphur compounds of molybdenum.

Using frequency instead of wave length to indicate the spectral position of the radiations which cause the maximum change in electrical conductivity, it is found that in some instances there is a constant difference of the wave numbers analogous to the series relations of spectral lines.

The time required for recovery of equilibrium in electrical conductivity is close to twice the time of exposure.

Mechanical working of the material appears to lower the photoelectric sensitivity.

There appears to be no close connection between photoelectric sensitivity and current rectification in molybdenite.

Measurements of reflecting power show that molybdenite has a high reflectivity in the violet, which decreases to a uniform value beyond $\mathrm{I} \mu$. Similarly, the transmission is high and uniform beyond $\mathrm{I} \mu$ in the infra-red. Using these data refractive indices were computed, indicating a value of $n=3$ for wave lengths greater than $\mathrm{I} \mu$.

The greatest photoelectrical activity occurs in the region of the spectrum, where there is a rapid decrease in spectral absorption. 


\section{A P P E N D IX}

\section{Appendix 1.-PHOTOELECTRIC ACTIVITY INDUCED IN UNILLUMINATED PARTS OF A CRYSTAL}

It was shown by Brown and Sieg ${ }^{39}$ that light falling upon one part of a crystal of selenium produced a change in conductivity throughout the crystal. In one sample this effect was produced by illuminating the crystal at a distance of 8 to $10 \mathrm{~mm}$ from the point of contact of the electrodes. Subsequent tests by Browri ${ }^{40}$ did not disclose whether this light action is transmitted as a result of change in crystalline structure, elastic vibration, or merely by diffusion.

This observation of a change in conductivity in portions of a crystal not directly illuminated has been tested also on cuprous oxide, by Pfund. ${ }^{41} \mathrm{He}$ found that if cuprous oxide shows this transmitted effect at all, it is infinitesimal in comparison with that observed in selenium.

It was of interest, therefore, to determine whether one part of a crystal of molybdenite undergoes a change in conductivity when another part of this same crystal is exposed to radiation. This test is best performed by illuminating a portion of the crystal which extends beyond the point of contact of the electrodes. In one test a platinum wire touching the surface of the molybdenite was used for one of the electrodes. When this platinum point was placed so that the exciting light fell between the two electrodes, the sample of molybdenite changed in conductivity, as indicated by the sound in the radiophone. On placing this platinum point so that the exciting light fell outside of these two electrodes no sound was produced in the radiophone. Various tests showed that illuminating one portion of a sensitive sample of molybdenite does not induce a change in conductivity in an unilluminated (but equally sensitive) portion of this same crystal. In other words, no change in conductivity appears to be produced by diffusion, internal reflection, etc., in molybdenite.

\section{Appendix 2.-POLARIZATION BY REFLECTION FROM MOLYBDENITE}

Pfund ${ }^{12}$ has shown that a selenium mirror provides an excellent means for producing polarized radiations. In view of the fact that molybdenite has a higher reflecting power than selenium, it was of interest to determine its polarizing properties. For this purpose two thin plates of molybdenite were mounted upon glass plates, as already described in the reflectivity measurements. The one was used as a polarizer and the other as an analyzer. These two mirrors were placed in an apparatus which permitted rotation of the analyzer. The source of (undispersed) radiation was a Nernst glower. The intensities were measured with a thermopile and galvanometer.

The galvanometer deflections were noted ( $\mathrm{r}$ ) when the planes of the polarizer and analyzer were parallel and (2) when they were crossed. Using mirrors of selenium, the ratio of the galvanometer deflections for these two positions (parallel: crossed) was of the order of $800: 1$; for maximum polarization.

${ }^{39}$ Brown and Sieg, Phil. Mag. (6), 28, p. 497; 1914.

40 Brown, Phys. Rev. (2), 5, p. 404; 1915.
41 Pfund, Phys. Rev. (2), 7, p. 296; 1916.

32 Pfund, Astrophys, Jr., 24, p. 19; 1906. 
Using mirrors of molybdenite for maximum polarization, the ratio of the galvanometer deflections for these two positions (parallel: crossed) was only about 8:1. Evidently molybdenite is not suitable for producing plane polarized light.

- In view of the high reflecting power of molybdenite it was of interest to determine whether it transforms plane into elliptically polarized light, as is true of a metal. The test was made with plane polarized radiations from a selenium mirror, which were reflected from the molybdenite mirror in the manner described by Pfund.

Preliminary tests with radiations transmitted by red glass showed that, for the spectral region from $\mathrm{I}$ to $4 \mu$, calcite reflects vitreously (i. e., does not transform plane into elliptically polarized light), as previously observed.

Similar tests on molybdenite, $\mathrm{MoS}_{2}$, showed that plane polarized radiations $(\lambda=I \mu$ to $4 \mu$ ) are elliptically polarized, the ellipticity (ratio of axes) being about $3:$ I. Similarly, a very flat cleavage surface of stibnite, $\mathrm{Sb}_{2} \mathrm{~S}_{3}$, produced an ellipticity of about $12: \mathrm{s}$.

These ratios are of course not very accurate, but they are consistent in that molybdenite is more metallic (judged by its elliptic polarization) than stibnite; àlso in having a higher reflecting power and especially a higher absorption coefficient. An investigation of the optical properties of substances like the above, which lie on the borderland between metals and nonmetals, would no doubt prove profitable.

Washington, December i 8, igrs. 